\title{
Discovery of a NAPE-PLD inhibitor that modulates emotional behavior in mice
}

\author{
Elliot D. Mock ${ }^{1}$, Mohammed Mustafa ${ }^{2}$, Ozge Gunduz-Cinar ${ }^{3}$, Resat Cinar ${ }^{4}$, Gavin N. Petrie ${ }^{5}$, \\ Vasudev Kantae ${ }^{1,6}$, Xinyu Di ${ }^{6}$, Daisuke Ogasawara ${ }^{7}$, Zoltan V. Varga ${ }^{8}$, Janos Paloczi ${ }^{8}$,

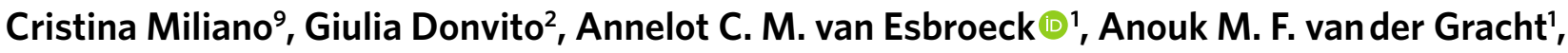 \\ Ioli Kotsogianni', Joshua K. Park ${ }^{4}$, Andrea Martella1, Tom van der Wel ${ }^{1,10}$, Marjolein Soethoudt ${ }^{1}$, \\ Ming Jiang ${ }^{1,10}$, Tiemen J. Wendel', Antonius P. A. Janssen ${ }^{1,10}$, Alexander T. Bakker', \\ Colleen M. Donovan ${ }^{3}$, Laura I. Castillo3, Bogdan I. Florea"1, Jesse Wat ${ }^{12}$, Helma van den Hurk' ${ }^{12}$, \\ Matthias Wittwer ${ }^{13}$, Uwe Grether ${ }^{13}$, Andrew Holmes ${ }^{3}$, Constant A. A. van Boeckel ${ }^{1,12}$, \\ Thomas Hankemeier ${ }^{6}$, Benjamin F. Cravatt $\mathbb{D}^{7}$, Matthew W. Buczynski ${ }^{9}$, Matthew N. Hill' \\ Pal Pacher ${ }^{8}{ }^{8}$, Aron H. Lichtman ${ }^{2,14}$ and Mario van der Stelt $\mathbb{1} 1,10 \bowtie$
}

$\mathbf{N}$-acylethanolamines (NAEs), which include the endocannabinoid anandamide, represent an important family of signaling lipids in the brain. The lack of chemical probes that modulate NAE biosynthesis in living systems hamper the understanding of the biological role of these lipids. Using a high-throughput screen, chemical proteomics and targeted lipidomics, we report here the discovery and characterization of LEI-401 as a CNS-active $\mathbf{N}$-acylphosphatidylethanolamine phospholipase D (NAPE-PLD) inhibitor. LEI-401 reduced NAE levels in neuroblastoma cells and in the brain of freely moving mice, but not in NAPE-PLD KO cells and mice, respectively. LEl-401 activated the hypothalamus-pituitary-adrenal axis and impaired fear extinction, thereby emulating the effect of a cannabinoid $\mathrm{CB}_{1}$ receptor antagonist, which could be reversed by a fatty acid amide hydrolase inhibitor. Our findings highlight the distinctive role of NAPE-PLD in NAE biosynthesis in the brain and suggest the presence of an endogenous NAE tone controlling emotional behavior.

\begin{abstract}
$\mathrm{n}$ recent years, lipids have come to the foreground as signaling mediators in the central nervous system $(\mathrm{CNS})^{1,2}$. While classical neurotransmitters are stored in synaptic vesicles and released on fusion with the plasma membrane of neurons, due to their lipophilic nature, lipids readily diffuse through membranes and are not stored in vesicles. It is, therefore, generally accepted that signaling lipids are produced 'on demand' and are rapidly metabolized to terminate their biological action ${ }^{3}$. In particular, NAEs, including $\mathrm{N}$-palmitoylethanolamine (PEA), $N$-oleoylethanolamine (OEA) and the endocannabinoid anandamide ( $N$-arachidonoylethanolamine, AEA) have emerged as key lipid signaling molecules. Genetic deletion or pharmacological inhibition of the main NAE hydrolytic enzyme, fatty acid amide hydrolase (FAAH), revealed elevated anandamide, PEA and OEA levels in brain and implicated these molecules in the modulation of various physiological processes such as pain, stress, anxiety, appetite, cardiovascular function and inflammation ${ }^{4-7}$. The physiological effects resulting from perturbation of the production of anandamide and other NAEs in living
\end{abstract}

systems are, however, poorly studied, partly because of a lack of pharmacological tools to modulate their biosynthetic enzymes ${ }^{8}$.

NAPE-PLD is generally considered a principal NAE biosynthetic enzyme ${ }^{9,10}$. Biochemical and structural studies have demonstrated that NAPE-PLD is a membrane-associated, constitutively active zinc hydrolase with a metallo- $\beta$-lactamase fold ${ }^{11}$. The enzyme generates a broad range of NAEs by hydrolysis of the phosphodiester bond between the phosphoglyceride and the NAE in $\mathrm{N}$-acylphosphatidylethanolamines (NAPEs) ${ }^{12}$. Knockout (KO) studies have shown that the $\mathrm{Ca}^{2+}$-dependent conversion of NAPE to NAEs bearing both saturated and polyunsaturated fatty acyl groups are fivefold reduced in brain lysates from mice that genetically lack Napepld ${ }^{13}$. In accordance, reduced levels of saturated and mono-unsaturated NAEs were observed in the brains of NAPE-PLD $\mathrm{KO}$ mice ${ }^{13-15}$. Anandamide levels were not reduced in the transgenic model reported by Leung et al., which suggested the presence of compensatory mechanisms ${ }^{13}$. Indeed, multiple alternative biosynthetic pathways for anandamide have been discovered since ${ }^{10}$.

'Department of Molecular Physiology, Leiden Institute of Chemistry, Leiden University, Leiden, the Netherlands. ${ }^{2}$ Department of Pharmacology and Toxicology, Virginia Commonwealth University, Richmond, VA, USA. ${ }^{\text {L }}$ aboratory of Behavioral and Genomic Neuroscience, National Institute on Alcoholism and Alcohol Abuse (NIAAA), National Institute of Health (NIH), Bethesda, MD, USA. 'Laboratory of Physiologic Studies, NIAAA, NIH, Bethesda, MD, USA. ${ }^{5}$ Hotchkiss Brain Institute, University of Calgary, Calgary, Alberta, Canada. ${ }^{6}$ Analytical Biosciences and Metabolomics, Division of Systems Biomedicine and Pharmacology, Leiden Academic Centre for Drug Research, Leiden University, Leiden, the Netherlands. ${ }^{7}$ Department of Chemical Physiology, The Scripps Research Institute, La Jolla, CA, USA. ${ }^{~}$ Laboratory of Cardiovascular Physiology and Tissue Injury, NIAAA, NIH, Bethesda, MD, USA. ' 5 chool of Neuroscience, Virginia Polytechnic Institute and State University, Blacksburg, VA, USA. ${ }^{10}$ Oncode Institute, Leiden, the Netherlands. "Bio-organic Synthesis, Leiden Institute of Chemistry, Leiden University, Leiden, the Netherlands. ${ }^{12}$ Pivot Park Screening Centre B.V., Oss, the Netherlands. ${ }^{13}$ Roche Innovation Center Basel, F. Hoffman-La Roche Ltd, Basel, Switzerland. ${ }^{14}$ Department of Medicinal Chemistry, Virginia Commonwealth University, Richmond, VA, USA. $\otimes_{\mathrm{e}-\mathrm{mail}}$ m.van.der.stelt@chem.leidenuniv.nl 
Of note, two other NAPE-PLD KO strains have been generated, which did show a decreased brain anandamide content ${ }^{14,15}$. Constitutive genetic mouse models are, however, poorly suited to study the rapid and dynamic formation of NAEs and their biological functions. Potent CNS-active inhibitors of NAPE-PLD are currently not available. Previously described NAPE-PLD inhibitors lack the potency, selectivity and/or physicochemical properties to study the role of this enzyme in in vivo systems in an acute setting ${ }^{16-18}$. Thus, a need exists for pharmacological tools that inhibit NAE biosynthesis in the brain.

Here, we report the discovery of LEI-401 (1) as a brain active NAPE-PLD inhibitor. High-throughput screening (HTS) and a medicinal chemistry program led to the identification of LEI-401 as a potent and selective NAPE-PLD inhibitor. LEI-401 reduced a broad range of NAEs including anandamide in neuronal cells in a NAPE-PLD-dependent manner. Anandamide and other NAE levels were reduced in the brain of wild-type (WT) mice treated with LEI401, but not in NAPE-PLD KO mice. The compound activated the hypothalamus-pituitary-adrenal (HPA) axis and impaired extinction of an aversive memory in mice, thereby mimicking the effects of cannabinoid $\mathrm{CB}_{1}$ receptor antagonism. These behavioral effects were prevented by a FAAH inhibitor. Taken together, LEI-401 is a first-in-class brain active NAPE-PLD inhibitor that blocks NAE biosynthesis in the brain of freely moving mice, thereby revealing a possible endogenous tone of this lipid family in emotional behavior.

\section{Results}

New NAPE-PLD inhibitor chemotypes are identified by HTS. To identify new inhibitors for NAPE-PLD, we initiated a HTS campaign in collaboration with the European Lead Factory (Supplementary Table 1$)^{19}$. A previously reported fluorescent NAPE-PLD activity assay $^{20}$ using the surrogate substrate $N$-(6-(2,4-dinitrophenyl) amino)hexanoyl)-2-(4,4-difluoro-5,7-dimethyl-4-bora-3a,4adiaza-s-indacene-3-pentanoyl)-1-hexadecanoyl-sn-glycero-3-p hosphoethanol-amine triethylammonium salt (PED6) was converted to a HTS-compatible 1,536-well format (Fig. 1a). As an enzyme source, we used membrane fractions of human embryonic kidney 293T (HEK293T) cells that were transiently transfected with human NAPE-PLD (Supplementary Fig. 1). This resulted in a robust assay with a $Z^{\prime}=0.87$, a signal-to-background ratio of 6.7 and intraplate variability (coefficient of variability) of $<3.3 \%$. Approximately 350,000 compounds were screened at a single concentration $(10 \mu \mathrm{M})$ in 294 plates over $3 \mathrm{~d}$, affording 8,321 actives (using the cut-off value of $Z$ score $\leq-7$ ) (Fig. 1b,c). Hit validation at the same concentration yielded 3,885 confirmed actives. To reduce the number of compounds, the percentage effect on the enzyme activity $(\geq 40 \%)$ was used to obtain a list of 1,120 actives. Next, dose-response curves were generated in the presence and absence of $\mathrm{ZnSO}_{4}(100 \mu \mathrm{M})$ to remove promiscuous $\mathrm{Zn}^{2+}$-ion chelators, which yielded 352 hits. Visual inspection of the 352 compounds revealed the presence of potential assay interfering compounds that absorbed light within the visible wavelength; therefore, a second deselection assay was developed. The substrate PED6 was incubated with lysate to obtain the maximum fluorescent signal, followed by incubation with different concentrations of the confirmed actives to determine the ability of the compounds to quench the fluorescent signal under the primary assay conditions. Compounds demonstrating no effect (half-maximal inhibitory concentration with negative $\left.\log \left(\mathrm{pIC}_{50}\right)<5\right)$ in the second deselection assay were selected (Supplementary Table 2). The compounds were checked for purity $(>85 \%)$ and correct molecular weight by liquid chromatographymass spectrometry (LC-MS) analysis. This afforded a qualified hit list of five compounds (2-6) with four different chemotypes (Fig. 1d).

Hit optimization provides nanomolar inhibitor LEI-401. Compound 2 ( $N$-(cyclopropylmethyl)-2-(methyl(phenethyl)amino)6-morpholinopyrimidine-4-carbox-amide) displayed the most optimal biological and physicochemical characteristics (molecular weight of $396 \mathrm{Da}$, calculated partition coefficient $\mathrm{c}-\log P=3.84$ ) (Fig. 1d and Supplementary Table 2). On resynthesis, chemical analysis and retesting, the identity and submicromolar activity $\left(K_{\mathrm{i}}=0.30 \mu \mathrm{M}\right.$, $95 \% \mathrm{CI}=0.22-0.38 \mu \mathrm{M}$ ) of the hit was confirmed (Fig. 2 and Supplementary Notes). To improve the inhibitory activity of compound 2, a medicinal chemistry program was initiated in which 112 derivatives were synthesized. A full report of the medicinal chemistry program will be described elsewhere; however, in brief, we discovered that replacing the morpholine for a $(S)$-3-hydroxypyrrolidine (7) improved activity $\left(K_{\mathrm{i}}=0.086 \mu \mathrm{M}, 95 \% \mathrm{CI}, 0.058-0.14 \mu \mathrm{M}\right)$, while simultaneously decreasing lipophilicity $(\mathrm{c}-\log P=3.46)$ (Fig. 2a,b). The absolute configuration of the hydroxyl was not essential for binding, as the $(R)$-enantiomer $\mathbf{8}$ showed similar potency $\left(K_{\mathrm{i}}=0.11 \mu \mathrm{M}, 95 \% \mathrm{CI}, 0.096-0.13 \mu \mathrm{M}\right)$. Conformational restriction of the phenethylamine moiety to a $(S)$-3-phenylpiperidine (1) further increased the potency $\left(K_{\mathrm{i}}=0.027 \mu \mathrm{M}, 95 \% \mathrm{CI}, 0.021-\right.$ $0.033 \mu \mathrm{M})$, whereas its $(R)$-enantiomer 9 was three times less active $\left(K_{\mathrm{i}}=0.094 \mu \mathrm{M}, 95 \% \mathrm{CI}, 0.071-0.12 \mu \mathrm{M}\right)$ (Fig. 2b). In view of the biological activity profile, we decided to further characterize compound 1 (termed LEI-401).

To profile NAPE-PLD inhibitors in mouse models, we assessed whether LEI-401 showed any species difference using recombinant mouse NAPE-PLD expressed in HEK293T cells. LEI-401 retained activity on mouse NAPE-PLD in the PED6 assay, albeit at a reduced potency $\left(K_{\mathrm{i}}=0.18 \mu \mathrm{M}, 95 \% \mathrm{CI}, 0.15-0.21 \mu \mathrm{M}\right)$. Next, we investigated the activity of LEI-401 on NAPE-PLD in a secondary in vitro assay to confirm an on-target effect of the inhibitor. To this end, we measured the NAPE-PLD enzyme activity in brain lysates of WT and NAPE-PLD KO mice by quantifying the formation of NAE (C17:0) from a synthetic C17:0-NAPE using an LC-MS-based assay ${ }^{21}$. LEI-401 reduced C17:0-NAE formation using brain homogenates of WT mice, but not from KO mice (Supplementary Fig. 3), thereby confirming that NAPE hydrolysis and its inhibition by LEI-401 in ex vivo preparations is dependent on NAPE-PLD in mouse brain. Following this, we assessed the activity profile of LEI- 401 for the receptors and metabolic enzymes of the endocannabinoid system. No inhibitory activities were measured at $10 \mu \mathrm{M}$ for the cannabinoid receptors type 1 and type 2 (Supplementary Table 3 ) as well as for the other enzymes involved in anandamide biosynthesis and degradation, such as phospholipase A2 group 4E (PLA2G4E) and FAAH (Supplementary Table 4), respectively. In addition, LEI-401 did not inhibit enzymes involved in the biosynthesis and degradation of the other endocannabinoid 2-arachidonoylglycerol (2-AG), including diacylglycerol lipases (DAGL $\alpha$ or DAGL $\beta$ ), monoacylglycerol lipase (MAGL) and $\alpha, \beta$-hydrolase domain 6 (ABHD6) (Supplementary Table 4).

Photoaffinity labeling shows NAPE-PLD target engagement. To assess target engagement and selectivity of LEI-401 in cellular systems, we turned to a photoaffinity labeling approach, which was previously successfully applied for other metallo-enzymes ${ }^{22}$. Based on the structure-activity relationships of LEI-401, a photoactivatable alkyne probe (10) was synthesized in which the 3-phenyl-piperidine was replaced with a trifluoromethyl-diazirine-benzyl-piperazine as a photoreactive group (Fig. $3 \mathrm{a}$ and Supplementary Notes). In addition, the methylcyclopropyl group was substituted for a propargyl group to serve as a ligation handle to introduce reporter groups by copper(I)-catalyzed azide-alkyne cycloaddition (CuAAC, or 'click') chemistry to study target engagement. First, we confirmed that compound 10 inhibited NAPE-PLD with a $K_{\mathrm{i}}$ of $0.18 \mu \mathrm{M}(95 \% \mathrm{CI}, 0.11-0.27 \mu \mathrm{M})$ in the biochemical PED6-assay (Supplementary Fig. 4). To assess whether compound 10 was able to visualize NAPE-PLD, HEK293T cells were transfected with hNAPE-PLD-FLAG or control (mock) plasmid for $48 \mathrm{~h}$, followed by in situ treatment with compound $10(2 \mu \mathrm{M})$ for $30 \mathrm{~min}$ and then irradiated at $350 \mathrm{~nm}$ for $10 \mathrm{~min}$. After lysis and clicking of a Cy5- $\mathrm{N}_{3}$ fluorophore, the samples were resolved by SDS-polyacrylamide gel 


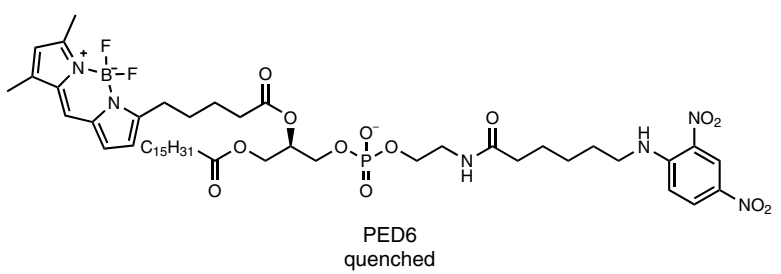

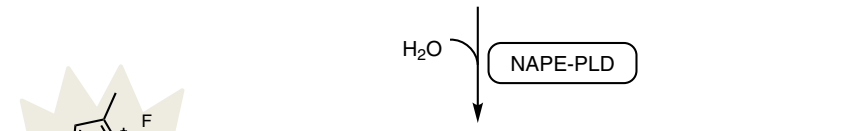

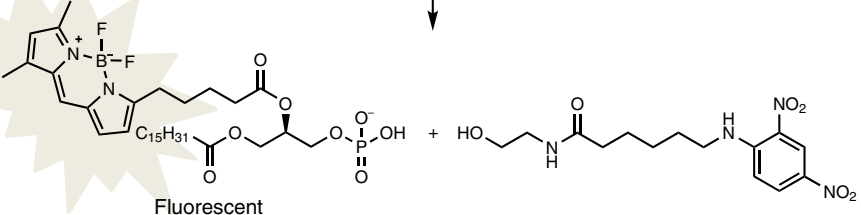

b

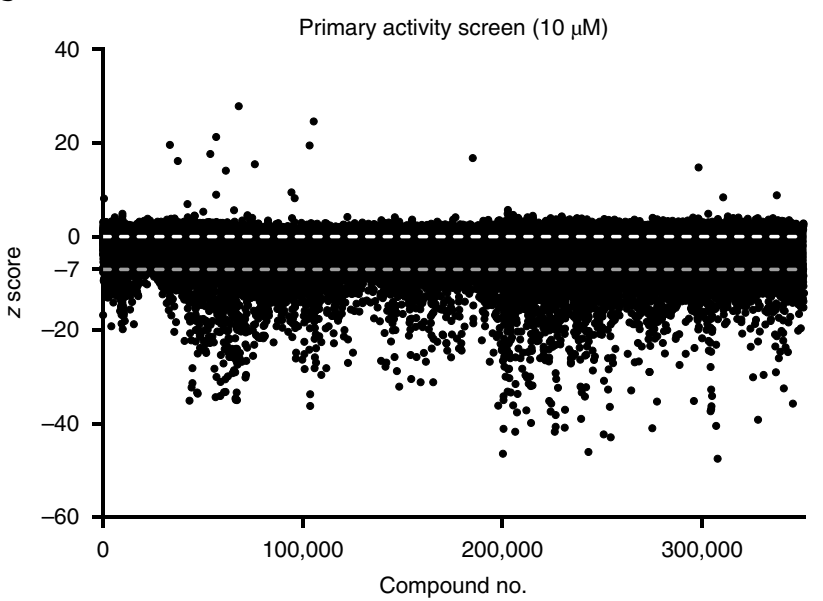

C

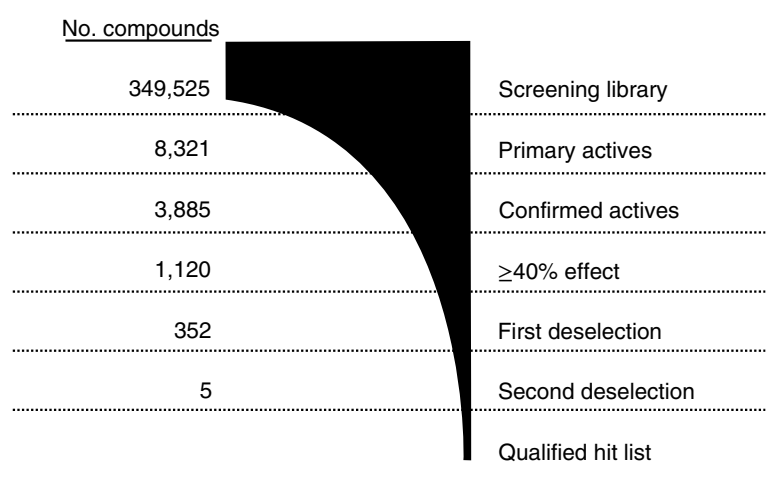

d

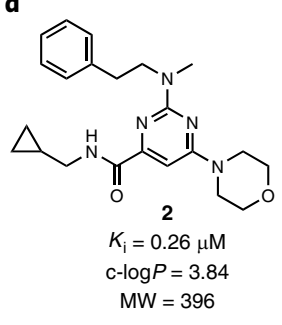

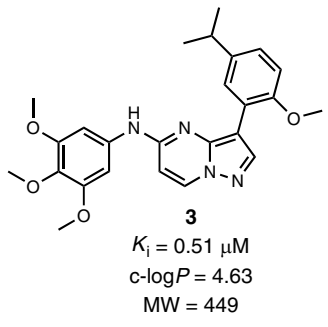

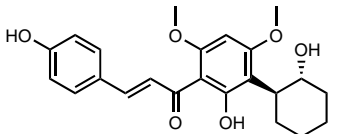

$K_{\mathrm{i}}=1.3 \mu \mathrm{M}$

$\mathrm{C}-\log P=3.42$ $\mathrm{MW}=398$
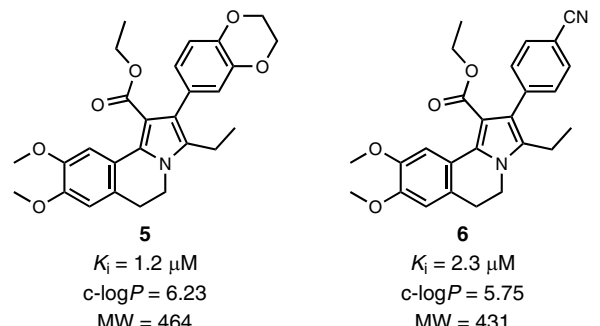

Fig. 1 | HTS of a NAPE-PLD activity assay provided potent new inhibitors 2-6. a, Cleavage of PED6 generated a fluorescent read-out of NAPE-PLD activity. $\mathbf{b}$, Primary activity screen. $\mathbf{c}$, Hit triage of the HTS campaign. d, Structures, potency data and physicochemical parameters of hit compounds (2-6). Data represent mean values \pm s.e.m. for two independent experiments with two biological replicates $(n=4)$. Dose-response curves are depicted in Supplementary Fig. 2. Complete HTS data are listed in Supplementary Tables 1 and 2.

electrophoresis (SDS-PAGE) and protein labeling was visualized by in-gel fluorescence scanning (Supplementary Fig. 5-7). An additional band at the expected molecular weight of $\sim 46 \mathrm{kDa}$ was apparent in the hNAPE-PLD-transfected cells but not in mock-treated cells, at the same height as the signal of an anti-FLAG antibody on western blot (Fig. 3b). The intensity of the fluorescent band at $46 \mathrm{kDa}$ was reduced on coincubation by the inhibitor LEI-401 (Fig. 3b), indicating that LEI-401 bound to NAPE-PLD in living cells. Concentration-response experiments revealed that LEI-401 dose-dependently reduced the labeling of NAPE-PLD with an $\mathrm{IC}_{50}$ of $0.86 \mu \mathrm{M}(95 \% \mathrm{CI}, 0.60-1.2 \mu \mathrm{M})$ (Fig. 3c,d). To establish the selectivity of LEI-401, a label-free chemical proteomics experiment was performed $^{23}$. Cell lysates prepared from hNAPE-PLD-transfected HEK293T cells incubated with photoprobe $\mathbf{1 0}$ were clicked with biotin- $\mathrm{N}_{3}$, which allowed for enrichment of probe-labeled proteins using avidin agarose beads, followed by trypsin digestion and protein identification by mass spectrometry. Proteomic analysis allowed identification of 136 proteins (Fig. 3e). NAPE-PLD was enriched by probe $\mathbf{1 0}$ in an ultraviolet (UV)-dependent manner and its labeling could be prevented by coincubation with LEI-401 (Fig. 3f). Furthermore, LEI-401 did not compete for other protein targets of probe $\mathbf{1 0}$ in this analysis or in mock-transfected
HEK293T cells (Fig. 3f and Supplementary Fig. 8). In summary, the development of photoaffinity probe $\mathbf{1 0}$ enabled the detection of NAPE-PLD in living cells and visualization of target engagement by LEI-401 with NAPE-PLD.

LEI-401 lowers NAEs in WT but not in NAPE-PLD KO cells. Having established that LEI-401 is a cell-permeable inhibitor and engages with NAPE-PLD, we then investigated whether LEI-401 inhibited endogenous NAPE-PLD in living cells. To this end, the mouse Neuro-2a neuroblastoma cell line was selected, since it expressed endogenous NAPE-PLD as determined by quantitative PCR (qPCR; Supplementary Table 5) and western blot using NAPE-PLD antibodies (Supplementary Fig. 9). Targeted lipidomics on lipid extracts of Neuro-2a cells allowed the quantification of eight different NAEs by LC-MS (Fig. 4a). As an appropriate negative control, two NAPE-PLD KO cell lines were generated using CRISPR/Cas9. The cell line KO-2 showed more efficient ablation of NAPE-PLD protein expression as demonstrated by western blot analysis compared to KO-1 and was therefore chosen for further analysis (Supplementary Fig. 9). Next, we incubated both WT and KO cells with LEI-401 $(10 \mu \mathrm{M})$ for $2 \mathrm{~h}$. A significant twofold reduction of anandamide was apparent in WT cells but not in NAPE-PLD KO 


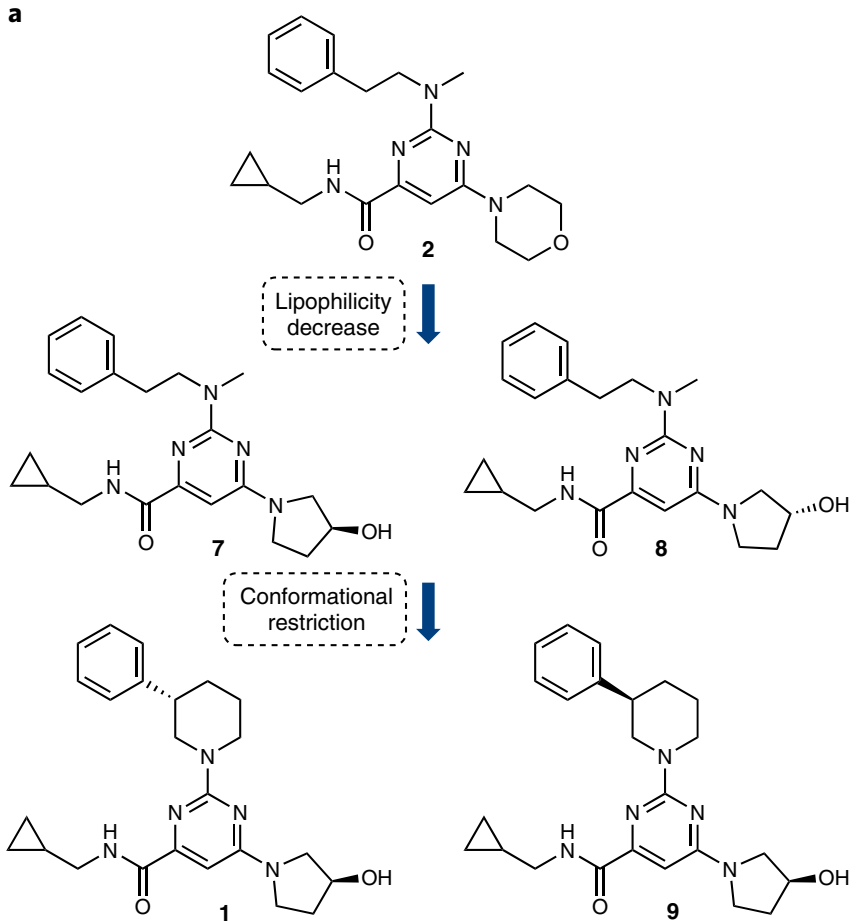

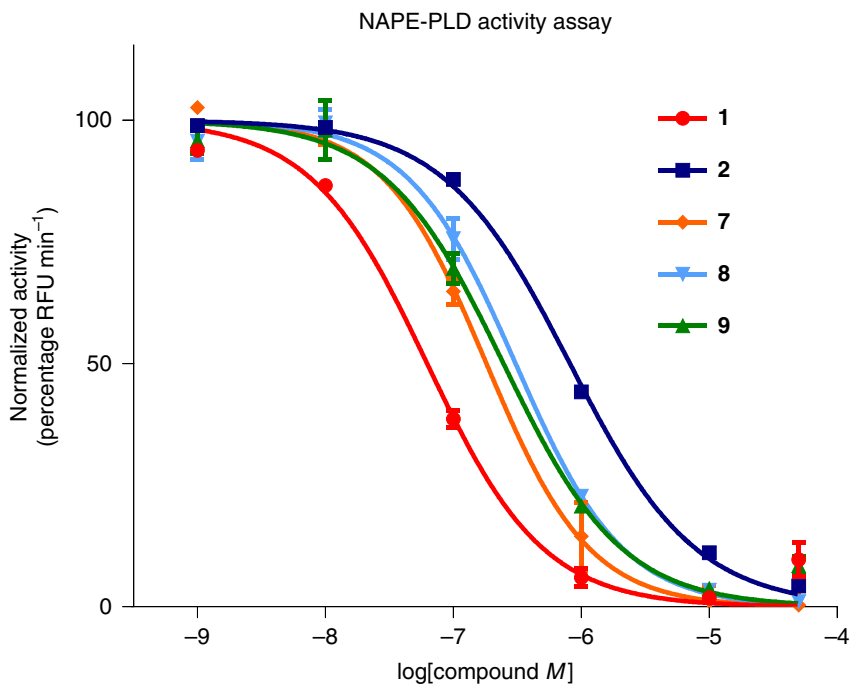

Fig. 2 | Hit optimization affords nanomolar potent inhibitor LEI-401. a, Respective substitution of the morpholine and $\mathrm{N}$-methylphenethylamine of 2 for a (S)-3-hydroxypyrrolidine and (S)-3-phenylpiperidine provided LEI-401. b, hNAPE-PLD in vitro activity assay dose-response curves for inhibitors 1 $\left(K_{\mathrm{i}}=0.027 \mu \mathrm{M}, 95 \% \mathrm{Cl} 0.021-0.033 \mu \mathrm{M}\right), \mathbf{2}\left(K_{\mathrm{i}}=0.30 \mu \mathrm{M}, 95 \% \mathrm{Cl} 0.22-0.38 \mu \mathrm{M}\right), \mathbf{7}\left(K_{\mathrm{i}}=0.086 \mu \mathrm{M}, 95 \% \mathrm{Cl} 0.058-0.14 \mu \mathrm{M}\right), \mathbf{8}\left(K_{\mathrm{i}}=0.11 \mu \mathrm{M}, 95 \% \mathrm{Cl}\right.$ $0.096-0.13 \mu \mathrm{M})$ and $\mathbf{9}\left(K_{\mathrm{i}}=0.094 \mu \mathrm{M}, 95 \% \mathrm{Cl} 0.071-0.12 \mu \mathrm{M}\right)$. Data represent mean values \pm s.e.m. for two independent experiments with two biological replicates $(n=4)$.

cells, indicating that the LEI-401-induced reduction in anandamide levels depended on expression of NAPE-PLD in Neuro-2a cells (Fig. 4b). LEI-401-treated cells did not show any sign of reduced cell viability (Supplementary Fig. 10). It is worth noting that the smaller but significant decrease of anandamide ( 25\%) in NAPE-PLD KO cells compared to WT may indicate the occurrence of compensatory mechanisms in the knockout cells, as also observed by others in Napepld-deficient mice (Supplementary Fig. 11a) ${ }^{13}$. Furthermore, other saturated, mono- and ( $\omega-6)$-polyunsaturated NAEs showed a similar twofold decrease in WT cells on LEI-401 pretreatment, but not in NAPE-PLD KO cells (Fig. 4b and Supplementary Fig. 11b-f). Of note, ( $\omega$-3)-polyunsaturated $N$-eicosapentanoylethanolamine (EPEA) and $N$-docosahexanoylethanolamine (DHEA) and did not respond to LEI-401 treatment (Fig. 4b and Supplementary Fig. 11g,h). Our data are in line with previously reported biochemical substrate studies using purified recombinant NAPE-PLD ${ }^{12}$ and indicate that endogenously expressed NAPE-PLD is responsible for biosynthesis of saturated, mono- and ( $\omega-6)$-polyunsaturated NAEs in Neuro-2a cells. The lack of effect on ( $\omega-3)$-polyunsaturated NAEs may suggest that these signaling lipids are produced via another pathway. Of note, recently it was found that dietary ( $\omega-3)$-polyunsaturated fatty acids augment NAE levels in mice via a pathway independent of NAPE-PLD ${ }^{24}$.

LEI-401 is brain-penetrant and reduces brain NAE levels. To assess whether LEI-401 possesses in vivo efficacy, we first determined its in vitro absorption, distribution, metabolism and excretion (ADME) profile. LEI-401 demonstrated favorable physicochemical properties for oral bioavailability and brain penetration (molecular weight of $422 \mathrm{Da} ; \log D=3.3$ and topological polar surface area of $\left.80.5 \AA^{2}\right)$. LEI-401 had low aqueous solubility $\left(1.7 \mathrm{mgl}^{-1}\right)$ and permeates well through membranes (parallel artificial membrane permeability assay (PAMPA) $P_{\text {eff }}=0.37 \mathrm{~nm} \mathrm{~s}^{-1}$ ). Clearance in human and mouse microsomes (10 and $42 \mu \mathrm{min}^{-1} \mathrm{mg}^{-1}$ protein, respectively) as well as in human and mouse hepatocytes $\left(6.9\right.$ and $28.8 \mu \mathrm{min}^{-1}$ per $10^{6}$ cells, respectively) was moderate, except for the low human microsomal clearance. LEI-401 exhibited high human and mouse protein binding of $>99.8 \%$. It is worth noting that it did not interact with either human or mouse PGP-transporter (efflux ratios were 1.7 and 1.8 , respectively).

Pharmacokinetic analysis in male C57BL/6J mice revealed a low clearance $\left(\mathrm{CL}=5.2 \mathrm{ml} \mathrm{min}^{-1} \mathrm{~kg}^{-1}\right)$ and moderate volume of distribution $\left(V_{\mathrm{ss}}=1.21 \mathrm{~kg}^{-1}\right)$, resulting in a half-life of $2.7 \mathrm{~h}$ (Fig. $5 \mathrm{a}$ and Supplementary Table 6). The low in vivo clearance was unexpected based on the in vitro clearance, but could be explained by the tight protein binding. Bioavailability after oral administration reached $25 \%$ and a more favorable bioavailability was achieved via intraperitoneal (i.p.) injection $\left(F_{\mathrm{ip}}=48 \%\right)$. In both cases, good plasma exposures were obtained. The brain to plasma ratio was 0.7 at $C_{\max }$ ( $2 \mathrm{~h}$ postinjection). This led to an excellent brain exposure $(>10 \mu \mathrm{M})$ after $30 \mathrm{mg} \mathrm{kg}^{-1}$ i.p. administration (Fig. 5b), which corresponds to approximately 70 -fold the mouse NAPE-PLD $K_{\mathrm{i}}$-value, and should be sufficient to modulate NAPE-PLD activity in mouse brain.

In view of the encouraging pharmacokinetic properties and brain exposure, we administered LEI-401 or vehicle to male C57BL/6J mice (30 $\mathrm{mg} \mathrm{kg}^{-1}$, i.p., single dose) and killed the mice after 1, 2, 4 or $8 \mathrm{~h}$ to determine whether NAE levels were reduced. To this end, we analyzed brain NAE levels by LC-MS. LEI-401 induced a significant and time-dependent reduction for anandamide $(P=0.0051)$, which was significant at $2 \mathrm{~h}$ and returned to vehicle level by $4 \mathrm{~h}$ (Fig. $5 \mathrm{c}$ ). A similar trend, although not significant, was observed for OEA and DHEA (Supplementary Fig. 12a,b). Next, mice were treated with various doses of LEI-401 (3,10 and $30 \mathrm{mg} \mathrm{kg}^{-1}$ or vehicle, i.p., single dose) and brain lipids were analyzed at $2 \mathrm{~h}$. LEI-401 $\left(30 \mathrm{mg} \mathrm{kg}^{-1}\right)$ significantly reduced anandamide (Fig. 5d). Other NAE lipid species showed a similar trend (Supplementary Fig. 13a-c). 


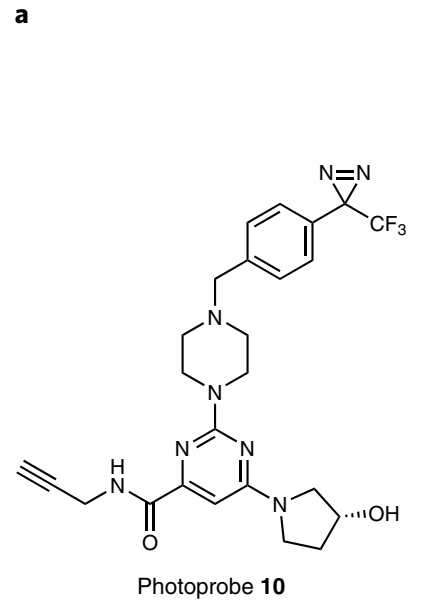

b Transfection $\frac{\mathrm{M}}{-} \frac{\mathrm{N}}{-} \frac{\mathrm{N}}{20}$

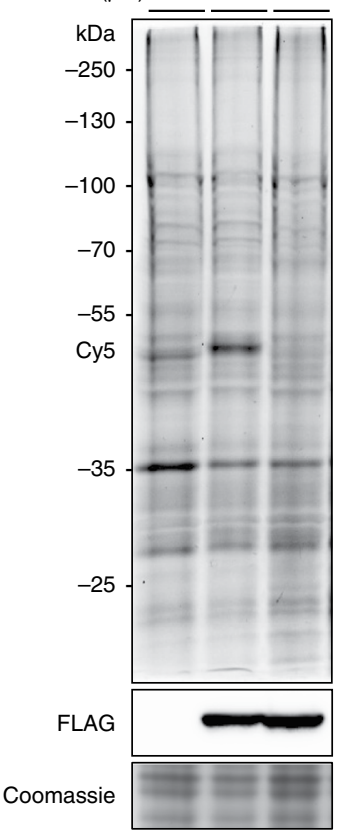

C

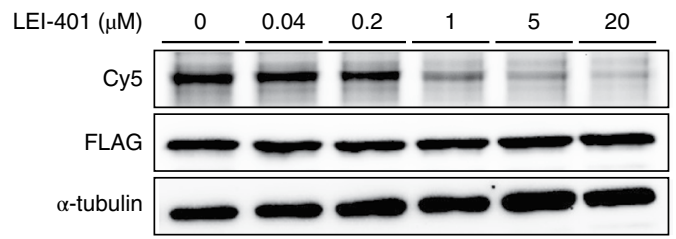

d
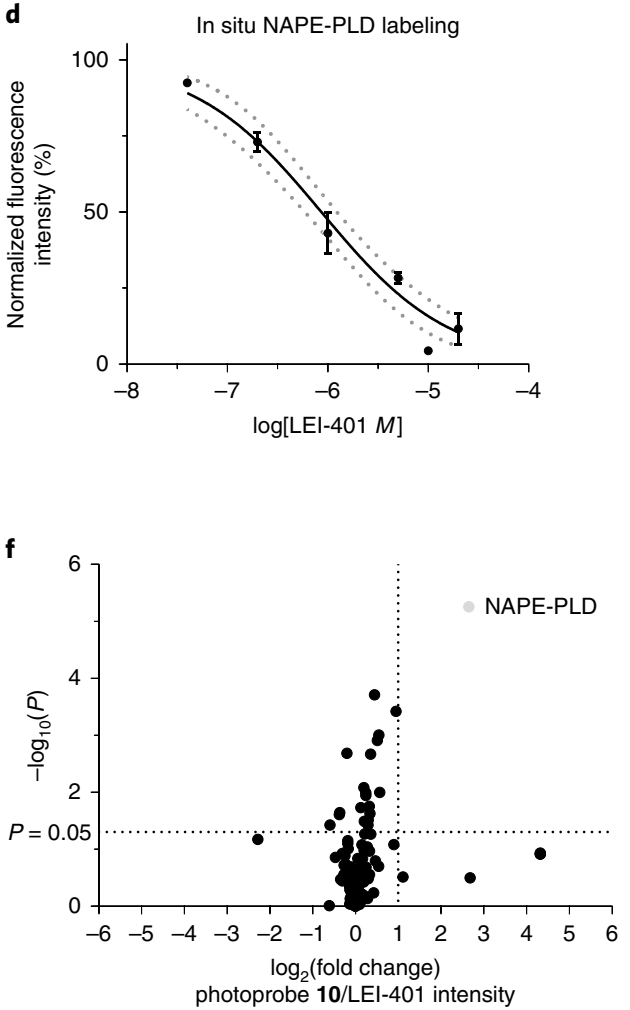

Fig. 3 | Photoprobe 10 visualizes target engagement of LEI-401 with NAPE-PLD in situ. a, Structure of NAPE-PLD photoprobe 10. b, Fluorescent labeling of hNAPE-PLD-FLAG at $\sim 46 \mathrm{kDa}$ in overexpressing HEK293T cells (middle lane) but not in mock-transfected cells (left lane) with photoprobe $\mathbf{1 0}$ ( $2 \mu \mathrm{M}$, $30 \mathrm{~min}$ ). The NAPE-PLD band was competed out by LEI-401 ( $20 \mu \mathrm{M}, 30 \mathrm{~min}$ coincubation) (right lane). Anti-FLAG western blot displays hNAPE-PLD-FLAG expression. M, mock; N, hNAPE-PLD-FLAG. Representative gel of three biologically independent experiments $(n=3)$. c, Dose-dependent competition of photoprobe $10(2 \mu \mathrm{M})$ with LEI-401 (30 min coincubation). Representative gel of three biologically independent experiments $(n=3)$. For $\mathbf{b}, \mathbf{c}$, Coomassie or $\alpha$-tubulin was used as a loading control. See Supplementary Figs. 6 and 7 for full gels and blots. d, Dose-response curve of LEl-401 with $95 \% \mathrm{Cl}$ (dotted lines); $\mathrm{IC}_{50}=0.86 \mu \mathrm{M}(95 \% \mathrm{Cl}, 0.60-1.2 \mu \mathrm{M})$. Data represent mean values \pm s.e.m. for three biological replicates $(n=3)$. e, Waterfall plot showing UV-enriched protein targets of photoprobe 10 in hNAPE-PLD-FLAG-transfected HEK293T cells (three biological replicates per condition ( $n=3$ )).

f. Volcano plot displaying competed protein targets for photoprobe $\mathbf{1 0}(2 \mu \mathrm{M})$ versus LEl-401 $(20 \mu \mathrm{M})$ in hNAPE-PLD-FLAG-transfected HEK293T cells (three biological replicates per condition $(n=3)$ ). Cut-off values used for $\mathbf{e}$,f: unique peptides $\geq 2 ; \log _{2}$ (fold change) $\geq 1$ (for $\mathbf{e}$, ratio $+U V /-U V$ intensity probe 10 and for $\mathbf{f}$, ratio photoprobe 10 intensity/LEI-401 intensity), $P<0.05$ using Student's $t$-test (unpaired, two-tailed) and Benjamini-Hochberg correction (10\% FDR).

The 2-AG levels were not significantly affected by LEI-401 treatment (30 $\mathrm{mg} \mathrm{kg}^{-1}$, i.p.) (Supplementary Figs. $12 \mathrm{c}$ and $13 \mathrm{~d}$ ). In line, the activity of the $2-A G$ producing and degrading enzymes DAGL $\alpha / \beta$, MAGL and ABHD6 in the brain was not affected (Supplementary Fig. 14). LEI-401 did not reduce brain NAE levels in NAPE-PLD KO mice (Supplementary Fig. 15a-c,f-h), which indicated that LEI-401 is a selective NAPE-PLD inhibitor. Of note, we found that anandamide levels were not decreased by LEI-401 in WT littermates of the NAPE-PLD KO animals, which originate from a mixed 129SvJ-C57BL/6 background, while PEA and OEA levels were significantly reduced (Supplementary Fig. 15f-h). This is in line with previous genetic studies using animals from the same background $^{13}$. Furthermore, 2-AG levels were increased in $\mathrm{KO}$ mice at a dose of $60 \mathrm{mg} \mathrm{kg}^{-1}$, whereas AA levels were decreased at this dose in animals of both genotypes (Supplementary Fig 15i,j). This indicated that at this high dose LEI-401 has an off-target that modulates 2-AG and AA levels. To determine whether acute inhibition of NAPE-PLD would affect its substrate levels, we determined NAPE and plasmalogen NAPE (pNAPE) levels in the brain of LEI401-treated mice. No change in NAPE or pNAPE species was found for LEI-401 compared to vehicle in both WT and NAPE-PLD KO mice (Supplementary Figs. 16 and 17). Collectively, these data indicate that LEI-401 is an in vivo active NAPE-PLD inhibitor that can be used to study its physiological role. 

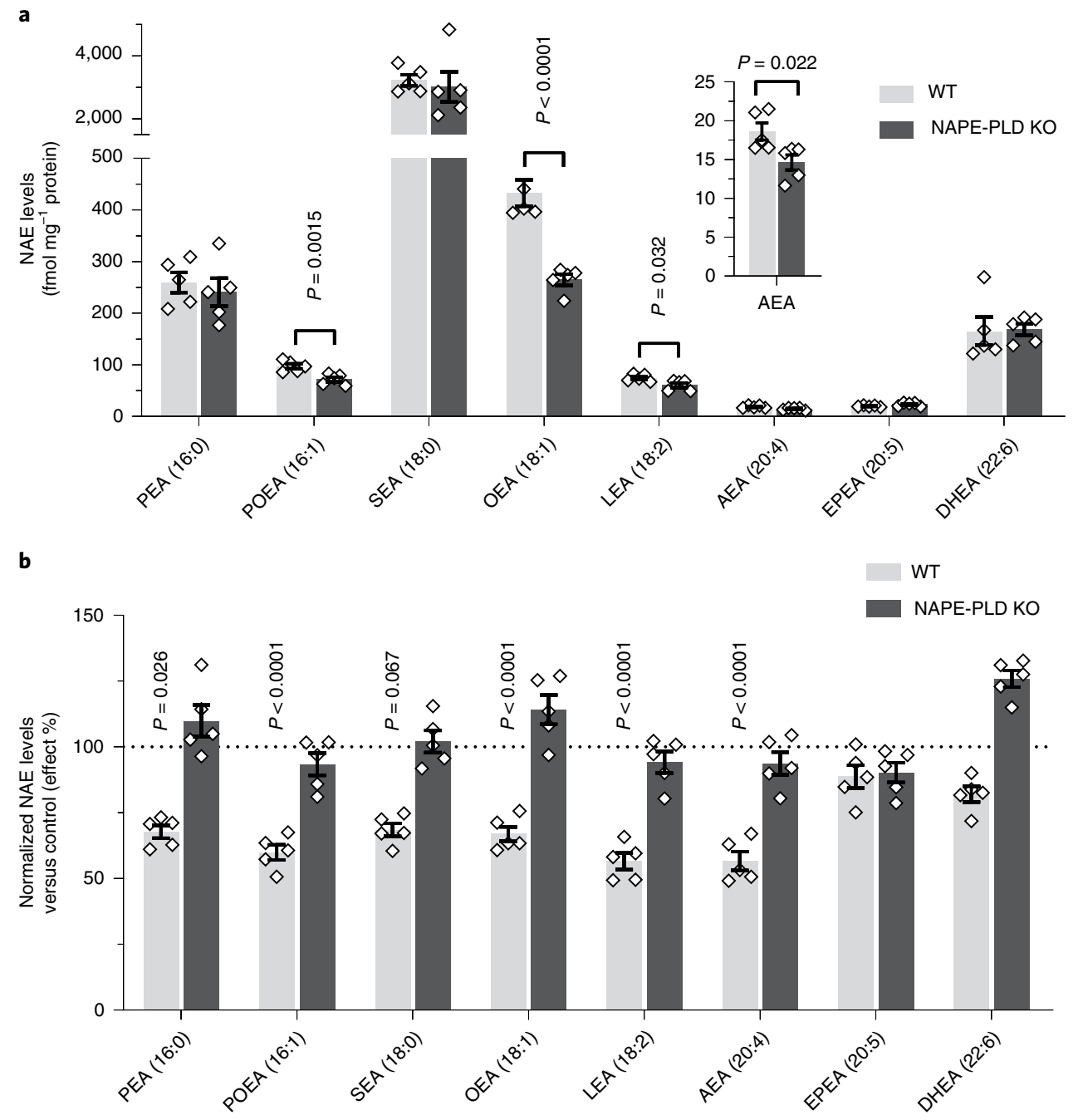

Fig. 4 | LEI-401 reduces NAE levels in Neuro-2a cells, but not in NAPE-PLD KO cells. a, Absolute NAE levels of Neuro-2a WT and NAPE-PLD KO cells. b. Relative NAE levels of Neuro-2a WT and NAPE-PLD KO cells treated with LEI-401 (10 $\mu \mathrm{M}, 2 \mathrm{~h})$, represented as effect percentage. Data were normalized against WT or NAPE-PLD KO cells treated with vehicle (DMSO). Absolute values for all NAEs are depicted in Supplementary Fig. 11. For $\mathbf{a}, \mathbf{b}$, data represent mean values \pm s.e.m. for five biological replicates $(n=5)$. $P$ values were calculated using one-way ANOVA with Tukey's multiple comparisons test.

LEI-401 modulates emotional behavior. NAEs are implicated in the regulation of emotional behavior, such as acute stress responses, anxiety and fear extinction ${ }^{6,25,26}$. It is hypothesized that a basal tone of anandamide, acting via the cannabinoid $\mathrm{CB}_{1}$ receptor, constrains activation of the HPA axis and controls the extinction of aversive memories ${ }^{5}$. This hypothesis is supported by experiments in which anandamide levels were elevated via pharmacological and genetic modulation of FAAH or by blocking the cannabinoid $\mathrm{CB}_{1}$ receptor $^{27-33}$. More so, stress exposure itself is known to reduce anandamide levels in vivo and reversal of this suppression of anandamide signaling, via inhibition of FAAH, is known to counter many effects of stress such as activation of the HPA axis and alterations in anxiety $^{34-36}$. Direct evidence that reducing NAE levels by pharmacological tools will affect emotional behavior has, however, not been obtained yet. LEI-401 is the first chemical probe that allows us to test this hypothesis. To this end, we first measured c-Fos protein expression in the paraventricular nucleus (PVN) of the hypothalamus, a primary integratory site for the HPA axis and a nucleus that is reliably activated by stress exposure, and determined circulating corticosterone (CORT) levels in mice $2.5 \mathrm{~h}$ after administration of LEI-401 (30 $\mathrm{mg} \mathrm{kg}^{-1}$, i.p., single dose), a $\mathrm{CB}_{1}$ receptor antagonist (AM251, $3 \mathrm{mg} \mathrm{kg}^{-1}$, i.p., single dose) or vehicle. PVN brain sections revealed that LEI-401 $(P<0.0001)$ and AM251 $(P=0.011)$ elevated c-Fos protein expression (Fig. 6a-d and Supplementary Fig. 18a-c). Notably, the effect of LEI-401 was reversed by cotreatment with the FAAH inhibitor URB597 (i.p., $1 \mathrm{mg} \mathrm{kg}^{-1}$, single dose; $P=0.016$ ) (Fig. 6c,d). Plasma CORT levels were significantly higher in LEI401-treated mice compared to control $(P=0.047)$, but not when cotreated with a FAAH inhibitor $(P=0.0027)$ (Fig. 6e). Similarly, an increase in plasma CORT was also observed for AM251-treated mice $(P=0.0042$; Supplementary Fig. $18 \mathrm{~d})$. These data suggest that NAPE-PLD provides a basal NAE tone, which restricts the activation of the HPA axis.

Next, to determine the consequences of depleting the endogenous NAE tone on a measure of emotional behavior, we tested LEI401 on mouse fear extinction ${ }^{37}$. First, C57BL/6J mice were trained to fear (quantified as freezing 'no movement else than breathing' levels) an auditory conditioned stimulus by repeated pairings with an unconditioned stimulus (US, footshock). One day after conditioning, mice were treated with LEI-401 (i.p., $30 \mathrm{mg} \mathrm{kg}^{-1}$, single dose), LEI-401 cotreatment with a FAAH inhibitor (AM3506, i.p., $1 \mathrm{mg} \mathrm{kg}^{-1}$, single dose) or vehicle $1 \mathrm{~h}$ and $45 \mathrm{~min}$ before a fear extinction training involving $50 \times$ conditioned stimulus presentations. A retrieval test was performed $10 \mathrm{~d}$ later to establish the duration of 


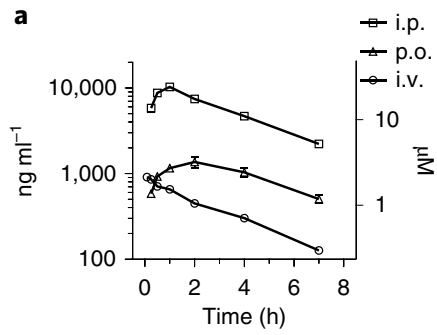

\section{b}

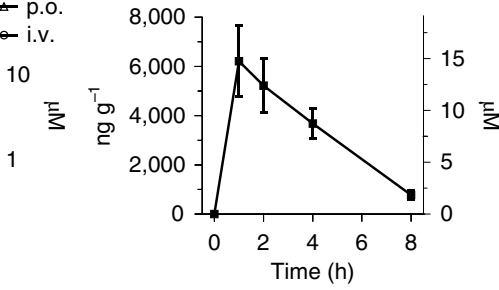

C

LEI-401(30 $\left.\mathrm{mg} \mathrm{kg}^{-1}\right)(\mathrm{h})$

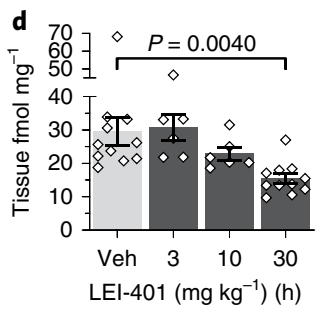

Fig. 5 | LEI-401 decreases AEA in mouse brain. a, In vivo pharmacokinetic profile of $\mathrm{LEI}-401$ in plasma of $\mathrm{C} 57 \mathrm{BL} / 6 \mathrm{~J}$ mice via intraperitoneal (i.p., $\left.30 \mathrm{mg} \mathrm{kg}^{-1}\right)$, p.o. (10 $\left.\mathrm{mg} \mathrm{kg}^{-1}\right)$ or i.v. $\left(1 \mathrm{mg} \mathrm{kg}^{-1}\right)$ administration. Data represent mean values \pm s.e.m. $n=5$ mice for time points 0.25 or $0.5 \mathrm{~h}$, and $n=3$ mice for 1, 2, 4 or 7 h. b, Brain pharmacokinetic profile of LEI-401 in $\mathrm{C} 57 \mathrm{BL} / 6 \mathrm{~J}$ mice after i.p. administration $\left(30 \mathrm{mg} \mathrm{kg}^{-1}\right)$. c, Time-dependent effect of LEI-401 on brain AEA. C57BL/6J mice i.p. injected with LEI$401\left(30 \mathrm{mg} \mathrm{kg}^{-1}\right)$. Veh, vehicle at $8 \mathrm{~h}$. For $\mathbf{b}$ and $\mathbf{c}$, data represent mean values \pm s.e.m. with $n=5$ mice for time points 1 or $2 \mathrm{~h}$, and $n=4$ mice for 4 or $8 \mathrm{~h}$. d, Dose-dependent effect of LEI-401 on brain AEA at $2 \mathrm{~h}$ after i.p. administration. Data represent mean values \pm s.e.m. with $n=5$ mice for dose groups 3 or $10 \mathrm{mg} \mathrm{kg}^{-1}$ and $n=11$ mice for vehicle or $30 \mathrm{mg} \mathrm{kg}^{-1}$. $P$ values were calculated using one-way ANOVA with Dunnett's multiple comparisons test.

extinction. This entailed $5 \times$ conditioned stimulus presentations (Supplementary Fig. 19). LEI-401 administration produced a significant increase in freezing as compared to vehicle $(P=0.0099)$, which was reversed by coadministration of a FAAH inhibitor (Fig. 6f). These results reveal a key contribution of NAPE-PLD in mediating fear extinction.

\section{Discussion}

NAEs, including anandamide, PEA and OEA, have emerged as an important class of lipid signaling molecules that regulate various physiological and behavioral functions via multiple mechanisms, including $\mathrm{G}$ protein-coupled receptors (cannabinoid $\mathrm{CB}_{1}$ receptor, GPR110 and GPR119), ion channels (TRPV1 and TASK-1) and nuclear receptors (PPAR- $\alpha)^{38}$. Inhibitors of NAE degradation have shed light on the role of NAEs in pain ${ }^{39}$, satiety ${ }^{40}$ and inflammation ${ }^{41}$, and emotional states such as fear ${ }^{6}$, stress ${ }^{29}$ and anxiety ${ }^{27}$. However, assessing the biological consequences of NAE reductions represent an important challenge because of a lack of selective inhibitors that block in vivo NAE production.

Here, we have addressed these important questions by developing LEI-401 as a brain active inhibitor of NAPE-PLD, an enzyme responsible for NAE biosynthesis. HTS and a medicinal chemistry program led to the discovery of LEI-401 as a potent and selective NAPE-PLD inhibitor with good pharmacokinetic properties. Acute NAPE-PLD inhibition by LEI-401 in mouse neuronal Neuro-2a cells decreased saturated, mono- and ( $\omega-6)$-polyunsaturated NAEs (including anandamide), while leaving ( $\omega-3)$-polyunsaturated NAEs unperturbed. This effect was not present in Neuro-2a cells lacking NAPE-PLD, showing the specificity of LEI-401. Notably, acute NAPE-PLD inhibition resulted in lower anandamide levels than observed in the knockout cells, thereby indicating that long-term inactivation of NAPE-PLD in cells also may lead to activation of compensatory pathways (Supplementary Fig. 11a). LEI-401 reduced NAE formation from synthetic NAPE ex vivo using brain lysates from WT mice, but not from NAPE-PLD KO mice. Administration of LEI-401 to mice resulted in a significant decrease in anandamide, PEA and OEA content in the brain. The LEI-401-mediated reductions in NAEs were absent in NAPE-PLD KO mice, thereby indicating that LEI-401 is a selective NAPE-PLD inhibitor. Of note, we found that anandamide levels were acutely reduced by LEI-401 in C57BL/6J mice, but not in animals derived from a mixed 129SvJ-C57BL/6J background. These observations are consistent with previous studies using the same mouse strains, in which genetic ablation of NAPE-PLD in C57BL/6J mice resulted in reduced anandamide levels, but not in mice with a mixed background $^{13,14}$. This reinforces the notion that besides NAPE-PLD alternative biosynthetic pathways exist for anandamide biosynthesis, which not only become apparent after long-term inactivation of the Napepld gene ${ }^{10,13}$, but also appear to be functional in normal physiological conditions depending on the genetic context. While the molecular factors that govern the biosynthesis of anandamide in mice originating from a $129 \mathrm{SvJ}-\mathrm{C} 57 \mathrm{BL} / 6 \mathrm{~J}$ background remain unknown at this time, it cannot be excluded that NAPE-PLD regulates anandamide biosynthesis in specific brain regions, cell types or other tissues in these mice. Regardless of the genetic context, our data indicate that LEI-401 is an in vivo active inhibitor that can be used to study the physiological role of NAPE-PLD. However, it should be noted that when studying the behavioral effects of LEI401 in relation to a reduction of anandamide levels it is important to take the genetic background of the animals into account.

LEI-401 provided us the opportunity to investigate the potential role of NAPE-PLD in emotional behavior. LEI-401 elicited a pronounced activation of the HPA axis, which was mimicked by a $\mathrm{CB}_{1}$ receptor antagonist and could be blocked by coadministration of a FAAH inhibitor. These findings support the hypothesis that a basal anandamide tone controls the activation of the HPA axis via the $\mathrm{CB}_{1}$ receptor $^{5}$. LEI-401 also impaired fear extinction, an effect that was rescued by a FAAH inhibitor, consistent with previous findings in which genetic deletion or pharmacological blockade of the $\mathrm{CB}_{1}$ receptor resulted in impaired fear extinction ${ }^{28,42-44}$. Taken together, our data are consistent with previous studies suggesting that anandamide may set an endogenous tone that plays a role in the neural circuitries mediating stress and fear behavior and provide experimental evidence that inhibition of NAPE-PLD is sufficient to modulate stress and fear. Whether the reduction of other NAEs, besides anandamide, also contribute to the observed behavioral effects of LEI-401 cannot be excluded at the moment ${ }^{26}$. Taken together, our data lend further preclinical support to test FAAH inhibitors in the clinic for stress-related disorders, such as posttraumatic stress disorder, which has been reported to exhibit reduced levels of anandamide ${ }^{45,46}$.

Finally, our studies indicate that LEI-401 and photoreactive probe 10 constitute a valuable toolbox to study various aspects of NAPE-PLD and NAE biology both in animal and in cellular models. Although LEI-401 was selective in a chemical proteomics setting, did not inhibit DAGL $\alpha$, DAGL $\beta$, MAGL and ABHD6, and did not affect NAE, 2-AG and AA levels in NAPE-PLD KO mice at $30 \mathrm{mg} \mathrm{kg}^{-1}$, it modulated brain 2-AG and AA levels at a higher dose of $60 \mathrm{mg} \mathrm{kg}^{-1}$ in both WT and KO mice. These observations indicate that LEI- 401 or its metabolites may have off-target activity and highlight the valuable role of combining chemical tools with genetic models to study on-target and off-target interactions of pharmacological agents. Second generation inhibitors will benefit from the identification of the off-targets. From a translational perspective, it will be interesting to study these inhibitors in various animal models of human disease, such as metabolic syndrome ${ }^{47}$, type II diabetes $^{48}$, neurodegeneration ${ }^{49}$, inflammatory and neuropathic pain ${ }^{50}$. The inhibitor reported in this study provided an opportunity 


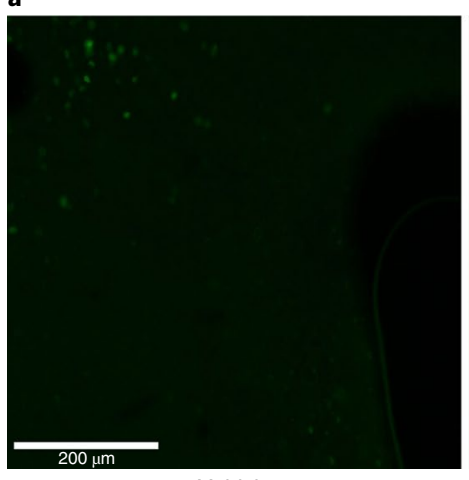

Vehicle

d

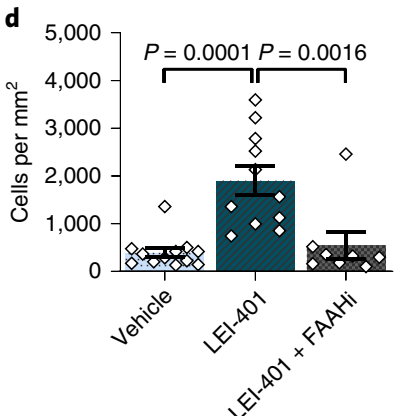

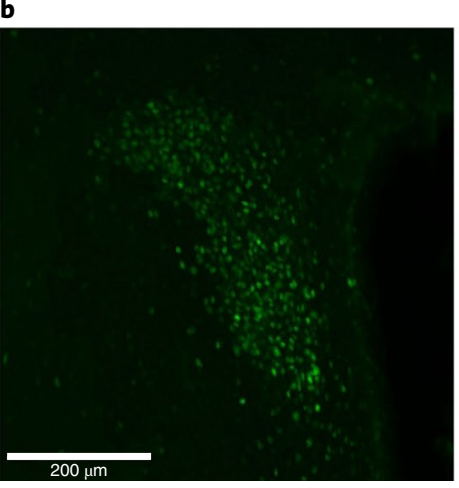

LEI-401

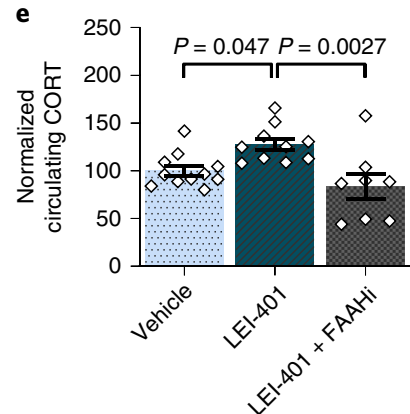

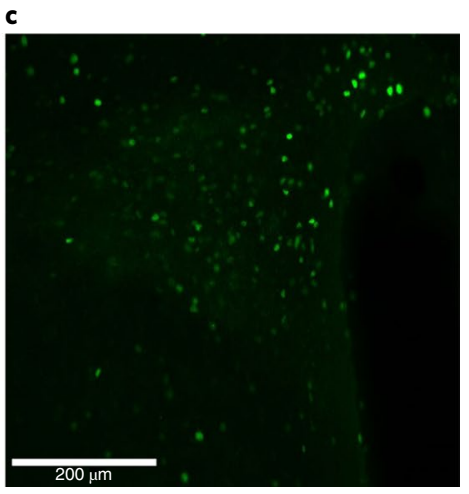

LEI-401 + FAAHi

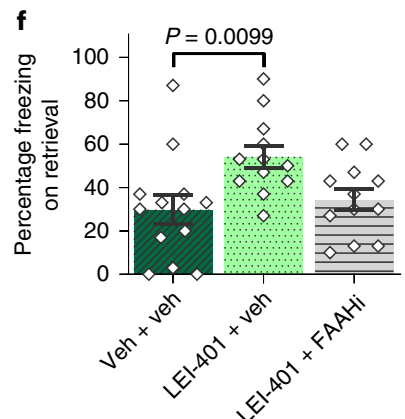

Fig. 6 | LEl-401 activates HPA axis signaling and diminishes fear extinction in vivo, which can be abolished by inhibition of FAAH. a-c, c-Fos labeling of brain sections of the PVN of the hypothalamus of mice treated with vehicle (a), LEl-401 (b) (i.p., 30 mg kg $^{-1}$, single dose) or LEl-401 with cotreatment of FAAH inhibitor URB597 (c) (i.p., $1 \mathrm{mg} \mathrm{kg}^{-1}$, single dose) 210 min before perfusion. Scale bars, $200 \mu \mathrm{m}$. d, Quantification of c-Fos labeled cells displayed a significant increase by LEI-401 and reversal by blockade of FAAH. For a-d, data represent mean values \pm s.e.m. with $n=12$ mice for vehicle treatment, $n=11$ mice for LEI-401 and $n=8$ mice for LEI-401+FAAHi. e, Circulating CORT levels were significantly elevated on LEI-401 treatment, but not when coadministered with the FAAH inhibitor URB597. Data represent mean values \pm s.e.m. with $n=11$ mice for vehicle treatment, $n=10$ mice for LEI-401 and $n=8$ mice for LEI-401+FAAHi. For a-e, $P$ values were calculated using one-way ANOVA with Tukey's multiple comparisons test. f, Freezing during the fear extinction memory retrieval test $10 \mathrm{~d}$ after treatment with vehicle or LEl-401 (i.p., $30 \mathrm{mg} \mathrm{kg}^{-1}$, single dose). LEl-401-treated mice exhibited increased freezing versus vehicle, but not when coadministered with FAAH inhibitor AM3506 (i.p., $1 \mathrm{mg} \mathrm{kg}^{-1}$, single dose). Data represent mean values \pm s.e.m. with $n=12$ mice for vehicle treatment and $n=10$ mice for LEI-401 or LEI-401+FAAHi. P values were calculated using one-way ANOVA with Dunnett's multiple comparisons test.

to investigate NAE biosynthesis in the brain of living animals in an acute and dynamic manner, thereby revealing a possible endogenous tone of this lipid family in emotional behavior. It is envisioned that LEI-401 may help to validate NAPE-PLD as a therapeutic target and serve as a starting point for the discovery of future drug candidates.

\section{Online content}

Any methods, additional references, Nature Research reporting summaries, source data, extended data, supplementary information, acknowledgements, peer review information; details of author contributions and competing interests; and statements of data and code availability are available at https://doi.org/10.1038/s41589020-0528-7.

Received: 12 February 2019; Accepted: 27 March 2020;

Published online: 11 May 2020

\section{References}

1. Hannun, Y. A. \& Obeid, L. M. Principles of bioactive lipid signalling: lessons from sphingolipids. Nat. Rev. Mol. Cell Biol. 9, 139 (2008).

2. Kano, M., Ohno-Shosaku, T., Hashimotodani, Y., Uchigashima, M. \& Watanabe, M. Endocannabinoid-mediated control of synaptic transmission. Physiol. Rev. 89, 309-380 (2009).

3. Alger, B. E. \& Kim, J. Supply and demand for endocannabinoids. Trends Neurosci. 34, 304-315 (2011).

4. Piomelli, D. \& Sasso, O. Peripheral gating of pain signals by endogenous lipid mediators. Nat. Neurosci. 17, 164 (2014).
5. Morena, M., Patel, S., Bains, J. S. \& Hill, M. N. Neurobiological interactions between stress and the endocannabinoid system. Neuropsychopharmacology 41, 80 (2015).

6. Lutz, B., Marsicano, G., Maldonado, R. \& Hillard, C. J. The endocannabinoid system in guarding against fear, anxiety and stress. Nat. Rev. Neurosci. 16, 705 (2015).

7. Pacher, P., Steffens, S., Haskó, G., Schindler, T. H. \& Kunos, G. Cardiovascular effects of marijuana and synthetic cannabinoids: the good, the bad, and the ugly. Nat. Rev. Cardiol. 15, 151-166 (2018).

8. Maccarrone, M. Metabolism of the endocannabinoid anandamide: open questions after 25 years. Front. Mol. Neurosci. 10, https://doi.org/10.3389/ fnmol.2017.00166 (2017).

9. Okamoto, Y., Morishita, J., Tsuboi, K., Tonai, T. \& Ueda, N. Molecular characterization of a phospholipase D generating anandamide and its congeners. J. Biol. Chem. 279, 5298-5305 (2004).

10. Hussain, Z., Uyama, T., Tsuboi, K. \& Ueda, N. Mammalian enzymes responsible for the biosynthesis of $N$-acylethanolamines. Biochim. Biophys. Acta 1862, 1546-1561 (2017).

11. Magotti, P. et al. Structure of human $N$-acylphosphatidylethanolaminehydrolyzing phospholipase D: regulation of fatty acid ethanolamide biosynthesis by bile acids. Structure 23, 598-604 (2015).

12. Wang, J. et al. Functional analysis of the purified anandamide-generating phospholipase $\mathrm{D}$ as a member of the metallo- $\beta$-lactamase family. J. Biol. Chem. 281, 12325-12335 (2006).

13. Leung, D., Saghatelian, A., Simon, G. M. \& Cravatt, B. F. Inactivation of $N$-acyl phosphatidylethanolamine phospholipase D reveals multiple mechanisms for the biosynthesis of endocannabinoids. Biochemistry 45, 4720-4726 (2006).

14. Tsuboi, K. et al. Enzymatic formation of $N$-acylethanolamines from $\mathrm{N}$-acylethanolamine plasmalogen through $\mathrm{N}$-acylphosphatidylethanolaminehydrolyzing phospholipase D-dependent and -independent pathways. Biochim. Biophys. Acta 1811, 565-577 (2011). 
15. Leishman, E., Mackie, K., Luquet, S. \& Bradshaw, H. B. Lipidomics profile of a NAPE-PLD KO mouse provides evidence of a broader role of this enzyme in lipid metabolism in the brain. Biochim. Biophys. Acta 1861, 491-500 (2016).

16. Petersen, G., Pedersen, A. H., Pickering, D. S., Begtrup, M. \& Hansen, H. S. Effect of synthetic and natural phospholipids on $N$-acylphosphatidylethanolamine-hydrolyzing phospholipase D activity. Chem. Phys. Lipids 162, 53-61 (2009).

17. Scott, S. A. et al. Discovery of desketoraloxifene analogues as inhibitors of mammalian, Pseudomonas aeruginosa, and NAPE phospholipase D enzymes. ACS Chem. Biol. 10, 421-432 (2015).

18. Castellani, B. et al. Synthesis and characterization of the first inhibitor of N-acylphosphatidylethanolamine phospholipase D (NAPE-PLD). Chem. Comm. 53, 12814-12817 (2017).

19. Karawajczyk, A., Orrling, K. M., de Vlieger, J. S. B., Rijnders, T. \& Tzalis, D. The European Lead Factory: a blueprint for public-private partnerships in early drug discovery. Front. Med. 3, https://doi.org/10.3389/fmed.2016.00075 (2017).

20. Peppard, J.V., Mehdi, S., Li, Z. \& Duguid, M.S. Assay methods for identifying agents that modify the activity of NAPE-PLD or ABH4. US patent WO2008150832A1 (2010).

21. Fu, J. et al. Food intake regulates oleoylethanolamide formation and degradation in the proximal small intestine. J. Biol. Chem. 282, 1518-1528 (2007).

22. Saghatelian, A., Jessani, N., Joseph, A., Humphrey, M. \& Cravatt, B. F Activity-based probes for the proteomic profiling of metalloproteases. Proc. Natl Acad. Sci. USA 101, 10000-10005 (2004).

23. van Rooden, E. J. et al. Mapping in vivo target interaction profiles of covalent inhibitors using chemical proteomics with label-free quantification. Nat. Protoc. 13, 752 (2018)

24. Lin, L. et al. Dietary fatty acids augment tissue levels of $\mathrm{N}$-acylethanolamines in $N$-acylphosphatidylethanolamine phospholipase D (NAPE-PLD) knockout mice. J. Nutr. Biochem. 62, 134-142 (2018).

25. Hill, M. N., Campolongo, P., Yehuda, R. \& Patel, S. Integrating endocannabinoid signaling and cannabinoids into the biology and treatment of posttraumatic stress disorder. Neuropsychopharmacology 43, 80 (2017).

26. Locci, A. \& Pinna, G. Stimulation of peroxisome proliferator-activated receptor- $\alpha$ by $N$-palmitoylethanolamine engages allopregnanolone biosynthesis to modulate emotional behavior. Biol. Psychiatry 85, 1036-1045 (2019).

27. Kathuria, S. et al. Modulation of anxiety through blockade of anandamide hydrolysis. Nat. Med. 9, 76 (2002).

28. Marsicano, G. et al. The endogenous cannabinoid system controls extinction of aversive memories. Nature 418, 530-534 (2002).

29. Hill, M. N. et al. Endogenous cannabinoid signaling is essential for stress adaptation. Proc. Natl Acad. Sci. USA 107, 9406-9411 (2010).

30. Gunduz-Cinar, O. et al. Convergent translational evidence of a role for anandamide in amygdala-mediated fear extinction, threat processing and stress-reactivity. Mol. Psychiatry 18, 813-823 (2013).

31. Dincheva, I. et al. FAAH genetic variation enhances fronto-amygdala function in mouse and human. Nat. Commun. 6, 6395 (2015).

32. Morena, M. et al. Upregulation of anandamide hydrolysis in the basolateral complex of amygdala reduces fear memory expression and indices of stress and anxiety. J. Neurosci. 39, 1275-1292 (2019).

33. Zimmermann, T. et al. Impaired anandamide/palmitoylethanolamide signaling in hippocampal glutamatergic neurons alters synaptic plasticity, learning, and emotional responses. Neuropsychopharmacology 44, 1377-1388 (2018)
34. Hill, M. N. et al. Suppression of amygdalar endocannabinoid signaling by stress contributes to activation of the hypothalamic-pituitary-adrenal axis. Neuropsychopharmacology 34, 2733 (2009).

35. Bluett, R. J. et al. Central anandamide deficiency predicts stress-induced anxiety: behavioral reversal through endocannabinoid augmentation. Transl. Psychiatry 4, e408-e408 (2014).

36. Gray, J. M. et al. Corticotropin-releasing hormone drives anandamide hydrolysis in the amygdala to promote anxiety. J. Neurosci. 35, 3879 (2015).

37. Gunduz-Cinar, O., Hill, M. N., McEwen, B. S. \& Holmes, A. Amygdala FAAH and anandamide: mediating protection and recovery from stress. Trends Pharmacol. Sci. 34, 637-644 (2013).

38. Tsuboi, K., Uyama, T., Okamoto, Y. \& Ueda, N. Endocannabinoids and related $\mathrm{N}$-acylethanolamines: biological activities and metabolism. Inflamm. Regen. 38, 28 (2018).

39. Ahn, K. et al. Discovery and characterization of a highly selective FAAH inhibitor that reduces inflammatory pain. Chem. Biol. 16, 411-420 (2009).

40. Fu, J. et al. Oleylethanolamide regulates feeding and body weight through activation of the nuclear receptor PPAR- $\alpha$. Nature 425, 90 (2003).

41. Solorzano, C. et al. Selective $N$-acylethanolamine-hydrolyzing acid amidase inhibition reveals a key role for endogenous palmitoylethanolamide in inflammation. Proc. Natl Acad. Sci. USA 106, 20966-20971 (2009).

42. Cannich, A. et al. CB1 cannabinoid receptors modulate kinase and phosphatase activity during extinction of conditioned fear in mice. Learn. Mem. 11, 625-632 (2004).

43. Suzuki, A. et al. Memory reconsolidation and extinction have distinct temporal and biochemical signatures. J. Neurosci. 24, 4787 (2004).

44. Chhatwal, J. P. et al. Functional Interactions between endocannabinoid and CCK neurotransmitter systems may be critical for extinction learning. Neuropsychopharmacology 34, 509-521 (2009).

45. Mayo, L. M. et al. Elevated anandamide, enhanced recall of fear extinction, and attenuated stress responses following inhibition of fatty acid amide hydrolase: a randomized, controlled experimental medicine trial. Biol. Psychiatry 87, 538-547 (2019).

46. Neumeister, A. et al. Elevated brain cannabinoid CB1 receptor availability in post-traumatic stress disorder: a positron emission tomography study. Mol. Psychiatry 18, 1034-1040 (2013).

47. Geurts, L. et al. Adipose tissue NAPE-PLD controls fat mass development by altering the browning process and gut microbiota. Nat. Commun. 6, 6495 (2015)

48. Jourdan, T. et al. Activation of the Nlrp3 inflammasome in infiltrating macrophages by endocannabinoids mediates beta cell loss in type 2 diabetes. Nat. Med. 19, 1132 (2013).

49. Hansen, H. H., Ikonomidou, C., Bittigau, P., Hansen, S. H. \& Hansen, H. S. Accumulation of the anandamide precursor and other $\mathrm{N}$-acylethanolamine phospholipids in infant rat models of in vivo necrotic and apoptotic neuronal death. J. Neurochem. 76, 39-46 (2001).

50. Sousa-Valente, J. et al. Inflammation of peripheral tissues and injury to peripheral nerves induce differing effects in the expression of the calcium-sensitive $N$-arachydonoylethanolamine-synthesizing enzyme and related molecules in rat primary sensory neurons. J. Comp. Neurol. 525, 1778-1796 (2017)

Publisher's note Springer Nature remains neutral with regard to jurisdictional claims in published maps and institutional affiliations.

(c) The Author(s), under exclusive licence to Springer Nature America, Inc. 2020 


\section{Methods}

Cloning of plasmid DNA. Full length human cDNA of human or mouse NAPEPLD (obtained from N. Ueda ${ }^{9}$ ), hDAGL $\alpha$, mDagl $\alpha, m D a g l \beta, h M A G L$ and $h P L A 2 G 4 E$ was cloned into mammalian expression vector pcDNA3.1, containing a C-terminal FLAG-tag and genes for ampicillin and neomycin resistance. All plasmids were grown in XL-10 Z-competent cells and prepped (Maxi Prep, Qiagen). Constructs were verified by Sanger sequencing (Macrogen).

Cell culture. HEK293T or Neuro-2a cells (ATCC) were cultured at $37^{\circ} \mathrm{C}$ and $7 \%$ $\mathrm{CO}_{2}$ in DMEM (Sigma Aldrich, D6546) with GlutaMax, penicillin $\left(100 \mu \mathrm{g} \mathrm{ml}^{-1}\right)$, streptomycin $\left(100 \mu \mathrm{g} \mathrm{ml}^{-1}\right)$ and $10 \%$ New Born Calf serum. Cells were passaged twice a week to appropriate confluence by thorough pipetting.

Transient transfection. One day before transfection, $10^{7}$ cells were seeded on a $15 \mathrm{~cm}$ dish, and $2 \mathrm{~h}$ before transfection, the medium was refreshed with $13 \mathrm{ml}$ medium. Transfection was performed with polyethyleneimine (PEI, $60 \mu \mathrm{g}$ per dish) in a ratio of 3:1 with plasmid DNA $(20 \mu \mathrm{g}$ per dish). The PEI and plasmid DNA were incubated in serum-free medium ( $2 \mathrm{ml}$ per dish) at room temperature for $15 \mathrm{~min}$, followed by dropwise addition to the cells. Transfection with the empty pcDNA3.1 vector was used to generate mock control samples. The medium was refreshed after $24 \mathrm{~h}$ and cells were collected after 48 or $72 \mathrm{~h}$ in cold PBS. Cells were centrifuged $\left(10 \mathrm{~min}, 200 \mathrm{~g}, 4^{\circ} \mathrm{C}\right)$ and the supernatant was removed. The cell pellets were flash frozen in liquid $\mathrm{N}_{2}$ and stored at $-80^{\circ} \mathrm{C}$.

Cell lysate preparation. Cell pellets were resuspended in lysis buffer: $20 \mathrm{mM}$ HEPES, $2 \mathrm{mM}$ DTT, $0.25 \mathrm{M}$ sucrose, $1 \mathrm{mM} \mathrm{MgCl}_{2}, 2.5 \mathrm{U} \mathrm{ml}^{-1}$ benzonase and incubated $30 \mathrm{~min}$ on ice. The cytosolic fraction (supernatant) was separated from the membranes by ultracentrifugation $\left(30 \mathrm{~min}, 100,000 \mathrm{~g}, 4^{\circ} \mathrm{C}\right)$. The pellet was resuspended in storage buffer comprising $20 \mathrm{mM}$ HEPES and $2 \mathrm{mM}$ DTT (membrane fraction). All samples were stored at $-80^{\circ} \mathrm{C}$. Protein concentrations were determined using a Bradford assay (Bio-Rad).

Mouse brain lysate preparation. Mouse brains were thawed on ice, dounce homogenized in cold lysis buffer (20 mM HEPES pH 7.2, $2 \mathrm{mM}$ DTT, $1 \mathrm{mM} \mathrm{MgCl}$, $2.5 \mathrm{U} \mathrm{ml}^{-1}$ benzonase) and incubated on ice for $(30 \mathrm{~min})$. The membrane and cytosolic fractions of cell or tissue lysates were separated by ultracentrifugation ( $45 \mathrm{~min}, 100,000 \mathrm{~g}, 4^{\circ} \mathrm{C}$ ). The supernatant was collected (cytosolic fraction) and the membrane pellet was resuspended in cold storage buffer (20 mM HEPES pH 7.2, $2 \mathrm{mM}$ DTT) by thorough pipetting and passage through a $1-\mathrm{ml}$ insulin needle. Protein concentrations were determined using a Bradford assay (Bio-Rad). All samples were stored at $-80^{\circ} \mathrm{C}$.

Western blot. Cell lysates were denatured with $4 \times$ Laemmli buffer (stock concentrations: $240 \mathrm{mM}$ Tris- $\mathrm{HCl}$ pH 6.8, $8 \%$ w/v SDS, $40 \%$ v/v glycerol, $5 \% \mathrm{v} / \mathrm{v}$ $\beta$-mercaptoethanol, $0.04 \% \mathrm{v} / \mathrm{v}$ bromophenol blue, $30 \mathrm{~min}$, room temperature) and $10-20 \mu \mathrm{g}$ per sample was resolved on a $10 \%$ acrylamide SDS-PAGE gel $(180 \mathrm{~V}, 75 \mathrm{~min})$. Proteins were transferred from the gel to a $0.2-\mu \mathrm{m}$ polyvinylidene difluoride membrane using a Trans-Blot Turbo (Bio-Rad). The membranes

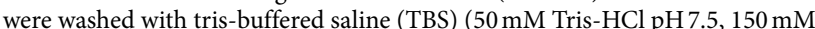
$\mathrm{NaCl}$ ) and blocked with 5\% milk in TBS and Tween 20 (TBST) $(50 \mathrm{mM}$ Tris- $\mathrm{HCl}$ $\mathrm{pH} 7.5,150 \mathrm{mM} \mathrm{NaCl}, 0.05 \%$ Tween 20$) 1 \mathrm{~h}$ at room temperature or overnight at $4^{\circ} \mathrm{C}$. Primary antibodies against NAPE-PLD (Abcam, ab95397, 1:200, in TBST), FLAG-tagged proteins (Sigma Aldrich, F3165, 1:5,000 in 5\% milk in TBST), $\alpha$-tubulin (Genetex, GTX76511, 1:5,000 in 5\% milk in TBST) or $\beta$-actin (Abcam, ab8226, 1:5,000 in 5\% milk in TBST) were incubated $1 \mathrm{~h}$ at room temperature or overnight at $4{ }^{\circ} \mathrm{C}$. Membranes were washed with TBST and incubated with secondary antibodies: for NAPE-PLD, goat-antirabbit-HRP (Santa Cruz, sc$2030,1: 2,000$ in $5 \%$ milk in TBST); for FLAG-tagged proteins and $\beta$-actin, goat-antimouse-HRP (Santa Cruz, sc-2005, 1:5,000 in 5\% milk in TBST); for $\alpha$-tubulin, goat-antirat (Santa Cruz, sc-2032, 1:5,000 in 5\% milk in TBST). All secondary antibodies were incubated $1 \mathrm{~h}$ at room temperature or overnight at $4{ }^{\circ} \mathrm{C}$. Membranes were washed with TBST and TBS. The blot was developed in the dark using a luminol solution $(10 \mathrm{ml}, 1.4 \mathrm{mM}$ luminol in Tris- $\mathrm{HCl} \mathrm{pH} 7.5)$, ECL enhancer $\left(100 \mu \mathrm{l}, 6.7 \mathrm{mM}\right.$ para-hydroxycoumaric acid in DMSO) and $\mathrm{H}_{2} \mathrm{O}_{2}(3 \mu \mathrm{l}$, $30 \% \mathrm{w} / \mathrm{w}$ in $\mathrm{H}_{2} \mathrm{O}$ ). Chemiluminescence was visualized using a ChemiDoc Imaging System (Bio-Rad). Band intensity is normalized to $\alpha$-tubulin or $\beta$-actin using ImageLab software (Bio-Rad).

qPCR. RNA isolation and cDNA synthesis was conducted as follows: total RNA from Neuro-2a cells was extracted using Trizol reagent (ThermoFisher Scientific). Once isolated, RNA concentration and purity were determined by Nanodrop (Denovix Inc.). Subsequently, cDNA synthesis was carried out with Maxima $\mathrm{H}$ minus first strand cDNA synthesis kit (ThermoFisher Scientific) according to the manufacturer's instructions.

qPCR analysis was conducted as follows: $10 \mathrm{ng}$ of input cDNA was analyzed using SybrGreen qPCR master mix (Biotool) in combination with CFX96 optical thermal cycler (Bio-Rad). Data analysis was performed using CFX Manager software (Bio-Rad). Data are expressed in quantitation cycles $\left(C_{\mathrm{q}}\right)$ and standard deviation of three technical replicates.
Activity assays. Surrogate substrate-based fluorescence assay NAPE-PLD. The NAPE-PLD activity assay was based on a previously reported method with small alterations $\mathrm{s}^{20}$. The membrane fraction from transient overexpression of human or mouse NAPE-PLD in HEK293T cells was diluted to $0.4 \mu \mathrm{gl}^{-1}$ in assay buffer ( $50 \mathrm{mM}$ Tris- $\mathrm{HCl} \mathrm{pH} 7.5,150 \mathrm{mM} \mathrm{NaCl}, 0.02 \% \mathrm{v} / \mathrm{v}$ Triton X-100). The substrate PED6 (Invitrogen, D23739) $1 \mathrm{mM}$ stock in DMSO was consecutively diluted in DMSO $(10 \times)$ and in assay buffer $(10 \times)$ to make a $10 \mu \mathrm{M}$ working solution. Relevant concentrations of compound ( $100 \times$ working solution) were prepared in DMSO. The assay was performed in a black Greiner 96-well plate (flat bottom), final volume $100 \mu \mathrm{l}$. The compound or DMSO was incubated with membrane protein lysate

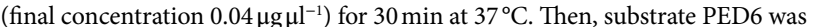
added (final concentration $1 \mu \mathrm{M}$ ) and the measurement was started immediately on a TECAN infinite $\mathrm{M} 1000$ pro at $37^{\circ} \mathrm{C}$ (excitation, $485 \mathrm{~nm}$; emission, $535 \mathrm{~nm}$; gain, 100), scanning every $2 \mathrm{~min}$ for $1 \mathrm{~h}$. Mock membrane lysate with DMSO was used for background subtraction. The slope of $t=4 \mathrm{~min}$ to $t=14 \mathrm{~min}$ was used as the enzymatic rate (relative fluorescence units (RFU per min), which was normalized to DMSO as $100 \%$. IC $_{50}$ curves were generated using Graphpad Prism v.6 (log (inhibitor) versus normalized response with variable slope). $K_{\mathrm{i}}$ values were calculated from the Cheng-Prusoff equation $K_{\mathrm{i}}=\mathrm{IC}_{50} /\left(1+\left((\mathrm{S}) / K_{\mathrm{M}}\right)\right)$ where $\mathrm{S}=$ [substrate] and $K_{\mathrm{M}}=0.59 \mu \mathrm{M}$ for both mouse and human NAPE-PLD. All measurements were performed in $n=4$ or $n=8$ for controls, with $Z \geq 0.6$.

\section{HTS of NAPE-PLD activity assay. Details of the HTS of the NAPE-PLD activity} assay are listed in Supplementary Table 1.

LC-MS-based endogenous NAPE-PLD activity assay. The NAPE-PLD assay to measure endogenous enzyme activity was performed as reported previously with small alterations using the synthetic substrate 1,2-dioleoyl-sn-glycero3-phosphoethanolamine- $N$-heptadecanoyl (C17:0-NAPE (19), for preparation see Supplementary Notes $)^{21}$. Mouse brain membrane lysates from male and female WT or NAPE-PLD KO mice (Virginia Polytechnic Institute and State University) were used originally generated by Leung et al. ${ }^{13}$. In an Eppendorf tube, per sample $10 \mu \mathrm{g}$ of mouse brain membrane lysate $\left(5 \mathrm{mg} \mathrm{ml}^{-1}\right)$ was diluted in assay buffer $(50 \mathrm{mM}$ Tris- $\mathrm{HCl} \mathrm{pH} 7.5+0.1 \%$ Triton X-100) to a final volume of $47 \mu \mathrm{l}$. As a negative control, a sample was denatured at $100^{\circ} \mathrm{C}$ for $10 \mathrm{~min}$ and cooled to room temperature for $5 \mathrm{~min}$. LEI-401 $(0.5 \mu \mathrm{l}, 100 \times$ in DMSO) or DMSO was added and incubated for $30 \mathrm{~min}$ at room temperature. C17:0-NAPE $(10 \mathrm{mM}$ stock in 9:1 $\left.\mathrm{CHCl}_{3}: \mathrm{MeOH}\right)$ was diluted in $\mathrm{EtOH}$ to $10 \mu \mathrm{M}$ and then added $(2.5 \mu \mathrm{l}, 20 \times$, $0.5 \mu \mathrm{M}$ final concentration). The samples were incubated at $37^{\circ} \mathrm{C}$ for $15 \mathrm{~min}$. Next, $10 \mu \mathrm{l}$ internal standard OEA-d $4(100 \mathrm{nM})$ was added, followed by $50 \mu 1 \mathrm{NH}_{4} \mathrm{OAc}$ buffer $(0.1 \mathrm{M}, \mathrm{pH} 4)$ and $500 \mu \mathrm{l} \mathrm{MTBE}$. The samples were vortexed using a Bullet Blender ( $4 \mathrm{~min}$, Next Advance Inc.) and centrifuged for $11 \mathrm{~min}$ at 16,000 $\mathrm{g}$ at $4{ }^{\circ} \mathrm{C}$. Then, $475 \mathrm{ml}$ of the supernatant was transferred to a new Eppendorf tube and evaporated to dryness. Reconstitution in $200 \mu$ lacetonitrile, vortex ( $3 \mathrm{~min}$ ) and centrifugation $(13,000 \mathrm{~g}, 2 \mathrm{~min})$. Following that, $50 \mu \mathrm{l}$ was transferred to an LC-MS vial with a micro insert. Next, $5 \mu$ l was injected in the LC-MS/MS system. A targeted analysis of C17:0 NAE was measured using an Acquity UPLC I class binary solvent manager pump in conjugation with a Xevo-TQ-S tandem quadrupole mass spectrometer (Waters Corporation). Separation of C17:0-NAE and OEA-d4 (internal standard) was performed with an Acquity HSS-T3 column $\left(2.1 \times 100 \mathrm{~mm}^{2}, 1.8 \mu \mathrm{m}\right.$ particle size; Waters Corporation $)$ maintained at $45^{\circ} \mathrm{C}$. The aqueous mobile phase A consisted of $2 \mathrm{mM}$ ammonium formate and $10 \mathrm{mM}$ formic acid, and the organic mobile phase $\mathrm{B}$ was acetonitrile. The flow rate was set to $0.6 \mathrm{ml} \mathrm{min}^{-1}$; initial gradient conditions were $70 \% \mathrm{~B}$ held for $0.50 \mathrm{~min}$ and linearly ramped to $100 \% \mathrm{~B}$ over $1.5 \mathrm{~min}$ and held for $1 \mathrm{~min}$; after $10 \mathrm{~s}$ the system returned to initial conditions and held for 2 min before the next injection. Electrospray ionization-MS was operated in positive mode for measurement of C17:0-NAE, and a selective multiple reaction mode was used for quantification. Data were analyzed with MassLynx v.4.1 software (Waters Corporation).

Natural substrate-based fluorescence assay DAGL $\alpha$. The natural substrate assay for human and mouse DAGL $\alpha$ was performed as reported previously ${ }^{51}$. All measurements were performed in $n=4$ or $n=8$ for controls, with $Z^{\prime} \geq 0.6$.

Surrogate substrate-based fluorescence assay DAGL $\beta$. The biochemical mDAGL $\beta$ assay was performed as reported previously ${ }^{52}$. All measurements were performed in $n=4$ or $n=8$ for controls, with $Z^{\prime} \geq 0.6$.

Natural substrate-based fluorescence assay MAGL. The natural substrate assay for human MAGL was performed as reported previously ${ }^{53}$. All measurements were performed in $n=4$ or $n=8$ for controls, with $Z^{\prime} \geq 0.6$.

Radioligand displacement assays $\mathrm{CB}_{1}$ and $\mathrm{CB}_{2}$ receptor. $\left[{ }^{3} \mathrm{H}\right] \mathrm{CP} 55940$ displacement assays to determine the affinity for the cannabinoid $\mathrm{CB}_{1}$ and $\mathrm{CB}_{2}$ were performed as previously described ${ }^{54}$.

Activity-based protein profiling (ABPP) for FAAH, ABHD6, ABHD12 and PLA2G4E activity. Gel-based ABPP was performed as previously described ${ }^{52}$. In brief, mouse brain membrane proteome or hPLA2G4E overexpressing membrane lysate 
(9.5 $\mu \mathrm{l}$ and $2 \mu \mathrm{g} \mu \mathrm{l}^{-1}$ or $19.5 \mu \mathrm{l}$ and $1 \mu \mathrm{g} \mu \mathrm{l}^{-1}$, respectively) was pre-incubated with vehicle or inhibitor $(0.5 \mu \mathrm{l} 20 \times$ or $0.5 \mu \mathrm{l} 40 \times$ inhibitor stock in DMSO, respectively, $30 \mathrm{~min}$, room temperature) followed by incubation with the activity-based probe MB064 (250 nM, $0.5 \mu \mathrm{l} 20 \times$ stock in DMSO) or FP-TAMRA (500 nM, $0.5 \mu \mathrm{l} 20 \times$ stock in DMSO) for mouse brain lysate (15 min, room temperature) or FP-TAMRA $(50 \mathrm{nM}, 0.5 \mu \mathrm{l} 40 \times$ stock in DMSO) for PLA2G4E overexpressing lysate ( $5 \mathrm{~min}$, room temperature). Final concentrations for the inhibitors are indicated in the main text and figure legends. Proteins were denatured with $4 \times$ Laemmli buffer $(3.5 \mu \mathrm{l}$, stock concentrations: $240 \mathrm{mM}$ Tris- $\mathrm{HCl} \mathrm{pH} 6.8,8 \% \mathrm{w} / \mathrm{v}$ SDS, $40 \% \mathrm{v} / \mathrm{v}$ glycerol, $5 \%$ $\mathrm{v} / \mathrm{v} \beta$-mercaptoethanol, $0.04 \% \mathrm{v} / \mathrm{v}$ bromophenol blue, $30 \mathrm{~min}$, room temperature). The samples (10 $\mu$ l per slot) were resolved by SDS-PAGE (respectively, 10 or $8 \%$ acrylamide for mouse brain or PLA2G4E lysate, $180 \mathrm{~V}, 75 \mathrm{~min}$ ). Gels were scanned using Cy 3 and Cy 5 multichannel settings (605/50 and 695/55 filters, respectively) on a ChemiDoc Imaging System (Bio-Rad). Fluorescence was normalized to Coomassie staining and quantified with ImageLab (Bio-Rad)

Generation of Neuro-2a NAPE-PLD KO populations. Single-guide RNA (sgRNA) selection. Two sgRNAs, located in exon 2 and 3 with high efficiency and specificity as predicted by CHOPCHOP v.2 online web tool (http://chopchop.cbu.uib.no) were selected. Guides were cloned into the BbsI restriction site of plasmid px330-U6-Chimeric_BB-CBh-hSpCas9 (gift from F. Zhang, Addgene plasmid no. 42230). The sgRNA targeting exon 3 yielded higher knockout efficiency as determined by western blot and in the T7E1-assays. This population was used for further experiments.

Sequential transfection. Neuro-2a cells were transfected sequentially (three times within the course of $10 \mathrm{~d}$ ) to yield populations with a high knockout efficiency. Cells were seeded at day 0 , day 3 and day 6 and transfected at day 1 , day 4 and day 7. Samples for T7E1 assays were collected at day 2, day 5, day 11 and after several weeks of culturing the cells.

One day before the first transfection, Neuro-2a cells were seeded to a six-well plate to reach $80-90 \%$ confluence at the time of transfection. Before transfection, culture medium was aspirated and $2 \mathrm{ml}$ of fresh medium was added. A 5:1 $(\mathrm{m} / \mathrm{m})$ mixture of PEI $(17.5 \mu \mathrm{g}$ per well) and plasmid DNA $(3.5 \mu \mathrm{g}$ per well $)$ was prepared in serum-free culture medium $(250 \mu \mathrm{l} \mathrm{each})$ and incubated $(15 \mathrm{~min}$, room temperature). Transfection was performed by dropwise addition of the PEI/ DNA mixture to the cells. Then, $24 \mathrm{~h}$ posttransfection, the culture medium was refreshed, a small number of cells were collected for analysis by T7E1 assay and ABPP while the remainder was kept in culture under standard conditions for following transfections. After three transfection rounds, the cells were cultured according to standard protocol.

T7E1 assay. Genomic DNA was obtained by mixing $50 \mu$ l QuickExtract (Epicentre) with cell pellet ( $\sim 10 \%$ of a well, from a six-well plate). The samples were incubated at $65^{\circ} \mathrm{C}$ for $6 \mathrm{~min}$, mixed by vortexing and then incubated at $98^{\circ} \mathrm{C}$ for $2 \mathrm{~min}$. Genomic DNA extracts were diluted in sterile water and directly used in PCR reactions. Genomic PCR reactions were performed on 2.5-5 $\mu$ l isolated genomic DNA extract using Phusion High-Fidelity DNA Polymerase (ThermoFisher) in Phusion HF buffer in a final volume of $20 \mu \mathrm{l}$, for primers see Supplementary Table 7.

For the T7E1 assay, genomic PCR products were denatured and reannealed in a thermocycler using the following program: $5 \mathrm{~min}$ at $95^{\circ} \mathrm{C}, 95$ to $85^{\circ} \mathrm{C}$ using a ramp rate of $-2^{\circ} \mathrm{C} \mathrm{s}^{-1}, 85-25^{\circ} \mathrm{C}$ using a ramp rate of $-0.2^{\circ} \mathrm{C} \mathrm{s}^{-1}$. To annealed PCR product $(8.5 \mu \mathrm{l})$ was added NEB2 buffer $(1 \mu \mathrm{l})$ and T7 endonuclease I ( $5 \mathrm{U}, 0.5 \mu \mathrm{l}$; New England Biolabs), followed by incubation at $37^{\circ} \mathrm{C}$ for $30 \mathrm{~min}$ Digested PCR products were analyzed using agarose gel electrophoresis with ethidium bromide staining.

Agarose gels were analyzed using ImageLab Software (Bio-Rad) and CRISPR gene editing efficiency was expressed as percentage T7E cleavage (volume integral of digested bands/volume integral all bands $\times 100 \%$ ).

Live cell photoaffinity labeling. Gel-based photoaffinity labeling. Here, 500,000 HEK293T cells per well were seeded in a 12-well plate $1 \mathrm{~d}$ before transfection. On the day of transfection, the medium was refreshed with $0.375 \mathrm{ml}$ medium per well. Transfection was performed with PEI ( $3 \mu \mathrm{g}$ per well) and human NAPEPLD-FLAG or mock pcDNA3.1Neo plasmids $(1 \mu \mathrm{g}$ per well). PEI and plasmids were combined in serum-free medium $(0.125 \mathrm{ml}$ per well $)$ and incubated for $15 \mathrm{~min}$ at room temperature, then added to each well. After $24 \mathrm{~h}$ the medium was refreshed. Then, $48 \mathrm{~h}$ after transfection, the medium was removed and cells were washed with warm PBS (1×). This was followed by treatment with photoprobe $\mathbf{1 0}(1,000 \times$ in DMSO, final concentration: $2 \mu \mathrm{M})$ together with vehicle or competitor $(600 \times$ in DMSO) in medium $+\operatorname{serum}\left(0.30 \mathrm{ml}\right.$ per well) for $30 \mathrm{~min}$ at $37^{\circ} \mathrm{C}$. The medium was aspirated and the cells were covered with PBS $(0.15 \mathrm{ml}$ per well), followed by $350 \mathrm{~nm}$ UV irradiation using a Caprobox at $4{ }^{\circ} \mathrm{C}$ for $10 \mathrm{~min}$. The cells were collected into $1.5 \mathrm{ml}$ epps with cold PBS and centrifuged for $10 \mathrm{~min}$ at 2,000 r.p.m. at $4{ }^{\circ} \mathrm{C}$. The PBS was removed and the cells were flash frozen with liquid $\mathrm{N}_{2}$ (cells can optionally be stored at $\left.-80^{\circ} \mathrm{C}\right)$. The cells were lysed with lysis buffer $(30 \mu \mathrm{l}, 20 \mathrm{mM}$ HEPES pH 7.2, $0.25 \mathrm{M}$ sucrose, $1 \mathrm{mM} \mathrm{MgCl}$, benzonase $25 \mathrm{U} \mathrm{ml}^{-1}$ ) followed by pipetting up and down and incubating for $30 \mathrm{~min}$ on ice. Protein concentrations were measured using a Bradford assay (Bio-Rad), and cell lysates were diluted to
$2 \mu \mathrm{g} \mu^{-1}$ with lysis buffer. Next, $18 \mu \mathrm{g}$ cell lysate $(9 \mu \mathrm{l})$ was then clicked with Cy5- $\mathrm{N}_{3}$ (for molecular structure see Supplementary Fig. 2) using a click mix ( $1 \mu \mathrm{l}$ per sample, final concentrations: $1 \mathrm{mM} \mathrm{CuSO}_{4}, 6 \mathrm{mM}$ sodium ascorbate, $0.2 \mathrm{mM}$ tris (3-hydroxypropyltriazolylmethyl)amine (THPTA), $2 \mu \mathrm{M} \mathrm{Cy} 5-\mathrm{N}_{3}$ ) for $1 \mathrm{~h}$ at room temperature (note that it is important to separately prepare the click mix first with $\mathrm{CuSO}_{4}$ and sodium ascorbate, until a yellow color change is observed). Samples were denatured with $4 \times$ Laemmli buffer $(3.33 \mu$ l, stock concentrations: $240 \mathrm{mM}$ Tris-HCl pH 6.8, 8\% w/v SDS, 40\% v/v glycerol, $5 \%$ v/v $\beta$-mercaptoethanol, $0.04 \% \mathrm{v} / \mathrm{v}$ bromophenol blue) and incubated for $30 \mathrm{~min}$ at room temperature. The samples were resolved by SDS-PAGE ( $10 \%$ acrylamide gel) at $180 \mathrm{~V}$ for $75 \mathrm{~min}$, after which the gels were imaged at Cy3 and Cy5 channels (605/50 and 695/55 filters, respectively) on a ChemiDoc Imaging System (Bio-Rad). Fluorescence is normalized to Coomassie or $\alpha$-tubulin by western blot using ImageLab software (Bio-Rad). $\mathrm{IC}_{50}$ curves were generated using Graphpad Prism v.6.

Chemical proteomics-based photoaffinity labeling. Here, $2 \times 10^{6}$ HEK293T cells per well were seeded in a six-well plate $1 \mathrm{~d}$ before transfection. On the day of transfection, the medium was removed and refreshed with $1.125 \mathrm{ml}$ fresh medium per well. Transfection was performed with PEI ( $9 \mu$ g per well) and human NAPEPLD-FLAG or mock pcDNA3.1Neo plasmids ( $3 \mu \mathrm{g}$ per well). PEI and plasmids were combined in serum-free medium $(0.375 \mathrm{ml}$ per well) and incubated for $15 \mathrm{~min}$ at room temperature, then added to each well. After $24 \mathrm{~h}$ the medium was refreshed. Next, $48 \mathrm{~h}$ after transfection, the medium was removed and cells were washed with warm PBS $(1 \times)$. This was followed by treatment with photoprobe $10(1,000 \times$ in DMSO, final concentration of $2 \mu \mathrm{M})$ together with vehicle or competitor $(1,000 \times$ in DMSO, final concentration $20 \mu \mathrm{M})$ in medium + serum $\left(1 \mathrm{ml}\right.$ per well) for $30 \mathrm{~min}$ at $37^{\circ} \mathrm{C}$. The medium was aspirated and the cells were covered with PBS ( $0.5 \mathrm{ml}$ per well), followed by $350 \mathrm{~nm}$ UV irradiation using a Caprobox at $4{ }^{\circ} \mathrm{C}$ for $10 \mathrm{~min}$. The cells were collected into 1.5 -ml epps with cold PBS and centrifuged for $10 \mathrm{~min}$ at 2,000 r.p.m. at $4{ }^{\circ} \mathrm{C}$. The PBS was removed and the cells were flash frozen with liquid $\mathrm{N}_{2}$ (cells can optionally be stored at $\left.-80^{\circ} \mathrm{C}\right)$. The cells were lysed with lysis buffer $(30 \mu \mathrm{l}, 20 \mathrm{mM}$ HEPES pH 7.2, $0.25 \mathrm{M}_{\text {sucrose, }} 1 \mathrm{mM} \mathrm{MgCl}_{2}$, benzonase $25 \mathrm{U} \mathrm{ml}^{-1}$ ) followed by pipetting up and down and incubating for $30 \mathrm{~min}$ on ice. Protein concentrations were measured using a Bradford assay (Bio-Rad), and cell lysates were diluted to $1 \mu \mathrm{g} \mu \mathrm{l}^{-1}$ with lysis buffer.

From here the label-free chemical proteomics protocol was followed as previously described ${ }^{30}$. Then, $270 \mu \mathrm{g}$ cell lysate $(270 \mu \mathrm{l})$ was clicked with biotin- $\mathrm{N}_{3}$ (Sigma Aldrich, 762024) using a click mix (30 $\mu$ l per sample, final concentrations: $1 \mathrm{mM} \mathrm{CuSO}_{4}, 6 \mathrm{mM}$ sodium ascorbate, $0.2 \mathrm{mM}$ tris (3-hydroxypropyltriazolylmethyl)amine (THPTA), $4 \mu \mathrm{M}$ biotin- $\mathrm{N}_{3}$ ) for $1 \mathrm{~h}$ at room temperature (note that it is important to separately prepare the click mix first with $\mathrm{CuSO}_{4}$ and sodium ascorbate, until a yellow color change is observed). Proteins were precipitated using chloroform $(166 \mu \mathrm{l})$, methanol $(666 \mu \mathrm{l})$ and MilliQ $\left(366 \mu \mathrm{l} \mathrm{H}_{2} \mathrm{O}\right)$. Samples were centrifuged for $10 \mathrm{~min}$ at $1,500 \mathrm{~g}$ and the solvents were carefully removed. Methanol $(600 \mu \mathrm{l})$ was added and the protein were resuspended using a probe sonicator $(30 \%$ amplitude, $10 \mathrm{~s})$. After centrifugation $(5 \mathrm{~min}, 18,400 \mathrm{~g})$ the solvent was removed and the samples were resuspended again in urea buffer $\left(250 \mu \mathrm{l}, 6 \mathrm{M}\right.$ urea, $\left.250 \mathrm{mM} \mathrm{NH}_{4} \mathrm{HCO}_{3}\right)$ by pipetting up and down. DTT $(2.5 \mu \mathrm{l}$, final concentration $10 \mathrm{mM}$ ) was added and the samples were incubated at $65^{\circ} \mathrm{C}$ with shaking (600 r.p.m.) for $15 \mathrm{~min}$. After cooling to room temperature, iodoacetamide $\left(20 \mu \mathrm{l}\right.$, final concentration $40 \mathrm{mM}$ ) was added and incubated in the dark at $20^{\circ} \mathrm{C}$ with shaking (600 r.p.m.) for $30 \mathrm{~min}$. Next, SDS $(70 \mu \mathrm{l}, 10 \%)$ was added and incubated at $65^{\circ} \mathrm{C}$ with shaking ( 600 r.p.m.) for $5 \mathrm{~min}$. For 18 samples, $1.8 \mathrm{ml}$ of avidin agarose beads (Thermo Scientific, 20219) were divided over three $15 \mathrm{ml}$ tubes and washed with PBS $\left(3 \times 10 \mathrm{ml}^{2}\right)$. The beads in each tube were resuspended in PBS $(6 \mathrm{ml})$ and divided over 18 tubes $(1 \mathrm{ml}$ each). To each tube was added the denatured sample and PBS $(2 \mathrm{ml})$ and the tubes were rotated with an overhead shaker at room temperature for $3 \mathrm{~h}$. After centrifugation $(2 \mathrm{~min}, 2,500 \mathrm{~g})$ and removal of the supernatant, the beads were consecutively washed with $0.5 \%$ SDS in PBS (w/v, $6 \mathrm{ml})$ and PBS $\left(3 \times 6 \mathrm{ml}^{2}\right)$, each time centrifuging $(2 \mathrm{~min}, 2,500 \mathrm{~g})$. The beads were transferred to a $1.5-\mathrm{ml}$ low binding epp (Sarstedt, 72.706.600) with on-bead digestion buffer $(2501,100 \mathrm{mM}$ Tris pH 8.0, $100 \mathrm{mM} \mathrm{NaCl}, 1 \mathrm{mM} \mathrm{CaCl}$, $2 \% \mathrm{v} / \mathrm{v}$ acetonitrile $)$ and to each sample was added $1 \mu \mathrm{l}$ trypsin solution $\left(0.5 \mu \mathrm{g} \mu \mathrm{l}^{-1}\right.$ trypsin (Promega, V5111), $0.1 \mathrm{mM} \mathrm{HCl}$ ). Proteins were digested at $37^{\circ} \mathrm{C}$ with shaking (950 r.p.m.) overnight. Formic acid ( $12.5 \mu \mathrm{l})$ was added to each sample and the beads were filtered off using a biospin column (Bio-Rad, 7326204), the flow-through was collected in a 2-ml epp. Samples were purified using StageTips. Each StageTip was conditioned with $\mathrm{MeOH}(50 \mu \mathrm{l}$, centrifugation: 2 min, $300 \mathrm{~g})$, followed by StageTip solution B $(50 \mu \mathrm{l}, 80 \% \mathrm{v} / \mathrm{v}$ acetonitrile, $0.5 \% \mathrm{v} / \mathrm{v}$ formic acid in MilliQ, centrifugation for $2 \mathrm{~min}, 300 \mathrm{~g})$ and StageTip solution A ( $50 \mu \mathrm{l}, 0.5 \% \mathrm{v} / \mathrm{v}$ formic acid in MilliQ, centrifugation for $2 \mathrm{~min}, 300 \mathrm{~g}$ ). Next, the samples were loaded, centrifuged $(2 \mathrm{~min}, 600 \mathrm{~g})$ and the peptides on the StageTip were washed with StageTip solution A $(100 \mu \mathrm{l}$, centrifugation for $2 \mathrm{~min}, 600 \mathrm{~g})$. The StageTips were transferred to a new $1.5 \mathrm{ml}$ low binding epp and the peptides were eluted with StageTip solution B $(100 \mu \mathrm{l}$, centrifugation for $2 \mathrm{~min}, 600 \mathrm{~g})$. The solvents were evaporated to dryness in a SpeedVac concentrator at $45^{\circ} \mathrm{C}$ for $3 \mathrm{~h}$. Samples were reconstituted in LC-MS solution ( $50 \mu \mathrm{l}, 3 \% \mathrm{v} / \mathrm{v}$ acetonitrile, $0.1 \% \mathrm{v} / \mathrm{v}$ formic acid, $1 \mu \mathrm{M}$ yeast enolase peptide digest (Waters, 186002325) in MilliQ). 
The peptides were measured as described previously for the NanoACQUITY UPLC System coupled to SYNAPT G2-Si high definition mass spectrometer ${ }^{30}$. A trap-elute protocol, where $5 \mu$ l of the digest was loaded on a trap column (C18 $100 \AA, 5 \mu \mathrm{M}, 180 \mu \mathrm{M} \times 20 \mathrm{~mm}$, Waters) followed by elution and separation on the analytical column (HSS-T3 C18 $1.8 \mu \mathrm{M}, 75 \mu \mathrm{M} \times 250 \mathrm{~mm}$, Waters). The sample was brought onto this column at a flow rate of $10 \mu \mathrm{min}^{-1}$ with $99.5 \%$ solvent A for $2 \mathrm{~min}$ before switching to the analytical column. Peptide separation was achieved using a multistep concave gradient based on gradients previously described $^{30}$. The column was re-equilibrated to initial conditions after washing with $90 \%$ solvent $\mathrm{B}$. The rear seals of the pump were flushed every $30 \mathrm{~min}$ with $10 \%(\mathrm{v} / \mathrm{v})$ acetonitrile. [Glu1]-fibrinopeptide B (GluFib) was used as a lock mass compound. The auxiliary pump of the LC system was used to deliver this peptide to the reference sprayer $\left(0.2 \mu \mathrm{lmin}^{-1}\right)$. A UDMSe method was set up as previously described ${ }^{30}$. Briefly, the mass range was set from 50 to 2,000 Da with a scan time of $0.6 \mathrm{~s}$ in positive, resolution mode. The collision energy was set to $4 \mathrm{~V}$ in the trap cell for low-energy MS mode. For the elevated energy scan, the transfer cell collision energy was ramped using drift-time specific collision energies. The lock mass was sampled every $30 \mathrm{~s}$. For raw data processing, PLGS (v.3.0.3) was used. The MS ${ }^{\mathrm{E}}$ identification workflow was performed with the parameters summarized in Supplementary Table 7 to search the human proteome from Uniprot (uniprot-homo-sapiens-trypsin-reviewed-2016_08_29.fasta). Protein quantification was performed using ISOQuant (v.1.5). The parameter settings used are summarized in Supplementary Table 7.

Data analysis. Protein targets of photoprobe 10 were selected based on the following cut-offs: ( 1$) \geq 2$-fold enrichment for UV-treated versus non-UV-treated samples; (2) unique peptides $\geq 2$; (3) testing for significance using Student's $t$-test (unpaired, two-tailed), $P<0.05$ was considered significant and (4) BenjaminiHochberg correction with a false discovery rate (FDR) of $10 \%$.

Targeted lipidomics in Neuro-2a cells. The targeted lipidomics experiments were based on previously reported methods with small alterations ${ }^{55}$.

Sample preparation. Here, $2 \times 10^{6}$ Neuro-2a cells (grown at $37^{\circ} \mathrm{C}, 7 \% \mathrm{CO}_{2}$ ) were seeded $1 \mathrm{~d}$ before treatment in $6 \mathrm{~cm}$ dishes. Before treatment, cells were washed twice with warm PBS and then treated with vehicle or compound $(10 \mu \mathrm{M}, 0.1 \%$ DMSO) in $3 \mathrm{ml}$ medium without serum $\left(2 \mathrm{~h}\right.$ at $37^{\circ} \mathrm{C}, n=5$ per condition). Washing with cold PBS $(1 \times)$ followed by gathering in $1.5 \mathrm{ml}$ Eppendorf tubes and centrifugation ( $10 \mathrm{~min}, 1,500$ r.p.m.). PBS was removed and the cell pellets were flash frozen with liquid nitrogen and stored at $-80^{\circ} \mathrm{C}$. Live cell count with trypan blue was performed after compound treatment to test for cell viability. Next, 10\% of each cell sample (collected during gathering) was used to determine the protein concentration using a Bradford assay (Bio-Rad) for normalization after lipid measurements.

Statistical analysis. Absolute values of lipid levels were corrected using the measured protein concentrations. Data were tested for significance with GraphPad v.6 using one-way analysis of variance (ANOVA) with Tukey correction for multiple comparisons. $P<0.05$ was considered significant.

In vitro ADME profile. Kinetic aqueous solubility (lyophilization solubility assay). The solubility of LEI-401 in phosphate buffer at pH 6.5 from an evaporated $10 \mathrm{mM}$ DMSO compound stock solution was measured. Two aliquots of the test compound were dried and dissolved in phosphate buffer at $\mathrm{pH}$ 6.5. The solutions were then filtered and diluted (three different dilution levels for each compound) before RapidFire MS analysis was performed. Each test compound was quantified using a six-point calibration curve prepared with the same DMSO starting solution.

Passive membrane permeability through PAMPA. PAMPA is a method that determines the permeability of substances from a donor compartment, through a lipid-infused artificial membrane into an acceptor compartment. Read-out is a permeation coefficient $P_{\text {eff }}$ drug as well as test compound concentrations in donor, membrane and acceptor compartments. The assay was performed as described elsewhere ${ }^{54}$.

Microsomal clearance. The microsomal clearance assay was performed as previously described ${ }^{54}$. Pooled commercially available microsome preparations from male mouse microsomes (C57BL/6J, Lot 4339006) were purchased from Corning Inc.). For human, ultrapooled liver microsomes (150 mixed gender donors, BD UltraPool HLM 150, Lot 38289) were purchased to account for the biological variance in vivo from human liver tissues. For the microsome incubations (incubation buffer 0.1 M phosphate buffer $\mathrm{pH} 7.4$ ), 96-deep well plates were applied, which were incubated at $37^{\circ} \mathrm{C}$ on a TECAN (Tecan Group Ltd) equipped with Te-Shake shakers and a warming device (Tecan Group Ltd). The reduced nicotinamide adenine dinucleotide phosphate regenerating system consisted of $30 \mathrm{mM}$ glucose-6-phosphate disodium salt hydrate; $10 \mathrm{mM}$ NADP. $30 \mathrm{mM} \mathrm{MgCl} \times 6 \mathrm{H}_{2} \mathrm{O}$ and $5 \mu \mathrm{g} \mathrm{\mu l}^{-1}$ glucose-6-phosphate dehydrogenase (Roche Diagnostics) in $0.1 \mathrm{M}$ potassium phosphate buffer $\mathrm{pH}$ 7.4. Incubations of LEI-401 at $1 \mu \mathrm{M}$ in microsome incubations of $0.5 \mu \mathrm{g} \mu \mathrm{l}^{-1}$ plus cofactor reduced nicotinamide adenine dinucleotide phosphate were performed in 96 -well plates at $37^{\circ} \mathrm{C}$. After $1,3,6,9,15,25,35$ and $45 \mathrm{~min} 40 \mu \mathrm{l}$ incubation solutions were transferred and quenched with $3: 1(\mathrm{v} / \mathrm{v})$ acetonitrile containing internal standards. Samples were then cooled and centrifuged before analysis by LC-MS/MS. The log peak area ratios (test compound peak area/internal standard peak area) were plotted against incubation time using a linear fit. The calculated slope was used to determine the intrinsic clearance: $\mathrm{CL}_{\text {int }}\left(\mu \mathrm{min}^{-1} \mathrm{mg}^{-1}\right.$ protein $)=-$ slope $\left(\mathrm{min}^{-1}\right) \times 1,000 /($ protein concentration $\left.\left(\mu g \mathrm{l}^{-1}\right)\right)$.

Hepatocyte clearance. The hepatocyte clearance assay was performed as previously described ${ }^{54}$. For animals, hepatocyte suspension cultures were either freshly prepared by liver perfusion studies or prepared from cryopreserved hepatocyte batches (pooled C57BL6 mouse hepatocytes were purchased from BioreclamationIVT). For human, commercially available, pooled (5-20 donors), cryopreserved human hepatocytes from nontransplantable liver tissues were used. For the suspension cultures, Nunc U96 PP-0.5 ml (Nunc Natural, 267245) plates were used, which were incubated in a Thermo Forma incubator from Fischer Scientific equipped with shakers from Variomag Teleshake shakers (Sterico) for maintaining cell dispersion. The cell culture medium was William's media supplemented with Glutamine, antibiotics, insulin, dexamethasone and 10\% FCS. Incubations of a test compound at $1 \mu \mathrm{M}$ test concentration in suspension cultures of $1 \times 10^{6}$ cells per $\mathrm{ml}\left(\sim 1 \mu \mathrm{g} \mu \mathrm{l}^{-1}\right.$ protein concentration $)$ were performed in 96 -well plates and shaken at 900 r.p.m. for up to $2 \mathrm{~h}$ in a $5 \% \mathrm{CO}_{2}$ atmosphere at $37^{\circ} \mathrm{C}$. After $3,6,10,20,40,60$ and $120 \mathrm{~min} 100 \mu \mathrm{l}$ cell suspension in each well was quenched with $200 \mu \mathrm{l}$ methanol containing an internal standard. Samples were then cooled and centrifuged before analysis by LC-MS/MS. The log peak area ratios (test compound peak area/internal standard peak area) or concentrations were plotted against incubation time with a linear fit. The slope of the fit was used to calculate the intrinsic clearance: $\mathrm{CL}_{\text {int }}\left(\mu 1 \mathrm{~min}^{-1} / 1 \times 10^{6}\right.$ cells $)=-$ slope $\left(\mathrm{min}^{-1}\right) \times 1,000$ / $\left(1 \times 10^{6}\right.$ cells $)$.

Plasma protein binding. The plasma protein binding assay was performed as previously described ${ }^{54}$. Pooled and frozen plasma from human (HMPLEDTA, lot BRH1060627) and mouse (MSEPLEDTA3-C57, lot MSE196204) were obtained from BioreclamationIVT. The Teflon equilibrium dialysis plate (96-well, $150 \mu \mathrm{l}$, half-cell capacity) and cellulose membranes (12-14kDa molecular weight cut-off) were purchased from HT-Dialysis (Gales Ferry). Both biological matrix and phosphate buffer $\mathrm{pH}$ were adjusted to 7.4 on the day of the experiment. The determination of unbound compound was performed using a 96-well format equilibrium dialysis device with a molecular weight cut-off membrane of $12-14 \mathrm{kDa}$. The equilibrium dialysis device itself was made of Teflon to minimize nonspecific binding of the test substance. Compounds were tested in cassettes of 2-5 with an initial total concentration of $1,000 \mathrm{nM}$, one of the cassette compounds being the positive control diazepam. Equal volumes of matrix samples containing substances and blank dialysis buffer (Soerensen buffer at $\mathrm{pH} 7.4$ ) were loaded into the opposite compartments of each well. The dialysis block was sealed and kept for $5 \mathrm{~h}$ at a temperature of $37^{\circ} \mathrm{C}$ and $5 \% \mathrm{CO}_{2}$ environment in an incubator. After this time, equilibrium has been reached for most small molecule compounds with a molecular weight of $<600$. The seal was then removed and matrix and buffer from each dialysis was prepared for analysis by LC-MS/MS. All protein binding determinations were performed in triplicate. The integrity of membranes was tested in the HT-Dialysis device by determining the unbound fraction values for the positive control diazepam in each well. At equilibrium, the unbound drug concentration in the biological matrix compartment of the equilibrium dialysis apparatus was the same as the concentration of the compound in the buffer compartment. Thus, the percentage unbound fraction $\left(f_{u}\right)$ was calculated by determining the compound concentrations in the buffer and matrix compartments after dialysis as follows: $\% f_{\mathrm{u}}=100 \times$ buffer concentration after dialysis/matrix concentration after dialysis. The device recovery was checked by measuring the compound concentrations in the matrix before dialysis and calculating the percent recovery (mass balance). The recovery must be within $80-120 \%$ for data acceptance.

P-glycoprotein active efflux assay. P-glycoprotein (permeability-glycoprotein, abbreviated to 'P-gp' and also known as multidrug resistance protein 1 (MDR1)) is the most-studied and best-characterized drug transporter. The P-gp assay evaluates the ability of test compounds to serve as a P-gp substrate. The assay was performed as described elsewhere ${ }^{54}$.

$\log D$-assay. For the determination of the octanol/water distribution coefficient $(\log D)$, the carrier-mediated distribution system-assay was used as described elsewhere ${ }^{54}$.

In vivo pharmacokinetics and lipidomics. Subjects. Male C57BL/6J mice (Jackson Laboratory) or male and female NAPE-PLD KO mice originally from a mixed 129SvJ-C57BL/6 J background (Virginia Polytechnic Institute and State University) generated by Leung et al. ${ }^{13}$ served as subjects for the in vivo pharmacokinetic and brain lipid analysis of LEI-401. Animal protocols were approved by 
the Institutional Animal Care and Use Committee at National Institute on Alcohol Abuse and Alcoholism, National Institute of Health, the Bundesamt für Lebensmittelsicherheit und Veterinärwesen (BLV) der Schweizerischen Eidgenossenschaft, the Dierexperimentencommissie Universiteit Leiden and by the Institutional Animal Care and Use Committee at Virginia Commonwealth University in accordance with the National Institutes of Health Guide for the Care and Use of Laboratory Animals ${ }^{56}$. All studies involving animals are reported in accordance with the Animal Research: Reporting of In Vivo Experiments guidelines for reporting experiments involving animals ${ }^{57}$.

Pharmacokinetic analysis of LEI-401 (mouse plasma). Test compounds were formulated according to respective protocols either by dissolution (intravenous, i.v.) or in a glass potter until homogeneity was achieved (oral (p.o.) and i.p.). Formulations were injected i.v. using a $30 \mathrm{G}$ needle in the lateral tail vein mice yielding a $1 \mathrm{mg} \mathrm{kg}^{-1}$ dose. For p.o. applications, animals were gavaged (yielding a $10 \mathrm{mg} \mathrm{kg}^{-1}$ dose) and for i.p. applications the compounds were injected into the abdomen (yielding a $30 \mathrm{mg} \mathrm{kg}^{-1}$ dose). At the following time points blood was drawn into EDTA: $0.083,0.25,0.5,1,2,4,7$ and $24 \mathrm{~h}$ (for p.o. and i.p. the first time point was omitted). Three animals each were used for the i.v. and p.o. arm and six animals were used in the i.p. arm. Animals were distributed randomly over the time course and at each time point, a volume of $100 \mu \mathrm{l}$ of blood was taken. Quantitative plasma measurement of the compound was performed by LC-MS/ MS analysis. Pharmacokinetic analysis was conducted using Phoenix WinNonlin v.6.4 software using a noncompartmental approach consistent with the route of administration. For assessment of the exposure $C_{\max }, T_{\max }$, area under curve and bioavailability were determined from the plasma concentration profiles. Parameters $\left(\mathrm{CL}, V_{\mathrm{ss}}, t_{1 / 2}\right)$ were estimated using nominal sampling times relative to the start of each administration.

Pharmacokinetic analysis of LEI-401 (mouse brain). Mice were injected with LEI401 (30 $\mathrm{mg} \mathrm{kg}^{-1}$, i.p., single dose) dissolved in sterile DMSO (D2650 Sigma) and mixed with Tween- 80 and distilled $\mathrm{H}_{2} \mathrm{O}$ at a ratio of $1: 1: 8$. Mice were killed after 1 , 2,4 and $8 \mathrm{~h}$. Brain samples were rapidly collected, washed in ice cold saline, blotted dry, frozen in liquid $\mathrm{N}_{2}$ and stored at $-80^{\circ} \mathrm{C}$ until further analysis. Brain levels of LEI-401 were quantified by LC-MS/MS using an Agilent 6410 triple quadrupole mass spectrometer (Agilent Technologies) coupled with an Agilent 1200 LC system (Agilent Technologies). Chromatographic and mass spectrometer conditions were set as described previously ${ }^{58}$. Chromatographic separation was obtained using 2.5- $\mu$ l samples injected onto a Zorbax SB-C18 rapid resolution HT column $\left(2.1 \times 50 \mathrm{~mm}^{2}, 1.8 \mu \mathrm{m}\right.$, Agilent $)$. The mass spectrometer was set for electrospray ionization in positive ion mode. The source parameters were as follows: capillary voltage, $4,000 \mathrm{~V}$; gas temperature, $350^{\circ} \mathrm{C}$; drying gas, $101 \mathrm{~min}^{-1}$; nitrogen was used as the nebulizing gas with a pressure of $40 \mathrm{psig}$. Collision-induced dissociation energy was performed by using nitrogen. Levels of LEI-401 were analyzed by multiple reactions monitoring. Mass spectrometric conditions were optimized for LEI-401 with injection of synthetic standard by using MassHunter Workstation Optimizer software (Agilent Technologies). The molecular ion and fragments for LEI-401 measured were as follows: $\mathrm{m} / z 422.26 \rightarrow 70.1$ and $422.26 \rightarrow 137$ (collision-induced dissociation energy, 56 and $40 \mathrm{~V}$, respectively). The amounts of LEI-401 in the samples were determined against standard curves. Values are expressed as $\mathrm{ng} \mathrm{g}^{-1}$ in wet brain tissue weight.

Lipid measurements in mouse brain. Levels of NAEs, 2-AG and arachidonic acid were measured by stable isotope dilution LC-MS/MS as described previously ${ }^{59}$.

In vitro ABPP of LEI-401-treated mice. Male C57BL/6J mice were treated with LEI-401 ( $30 \mathrm{mg} \mathrm{kg}^{-1}$, i.p., single dose) or vehicle (DMSO, Tween-80 and distilled $\left.\mathrm{H}_{2} \mathrm{O} ; 1: 1: 8\right)$ and killed after $2 \mathrm{~h}$ by cervical dislocation. Brain samples were rapidly collected, frozen in liquid $\mathrm{N}_{2}$ and stored at $-80^{\circ} \mathrm{C}$ until further analysis. After membrane lysate preparation (vide supra), $19.5 \mu \mathrm{l}$ lysate $\left(2 \mathrm{mg} \mathrm{ml}^{-1}\right)$ per sample was treated with $0.5 \mu \mathrm{l}$ probe $(40 \times$ stock in DMSO, final concentration $250 \mathrm{nM}$ for MB064, 500 nM for fluorescence polarization-boron dipyrromethene (BODIPY) $(1 \mu \mathrm{M}$ for DH379) and incubated for $15 \mathrm{~min}$ at room temperature or $30 \mathrm{~min}$ at $37^{\circ} \mathrm{C}$ for DH379. Proteins were denatured with $4 \times$ Laemmli buffer $(7.5 \mu$ l, stock concentrations: $240 \mathrm{mM}$ Tris- $\mathrm{HCl} \mathrm{pH} 6.8,8 \% \mathrm{w} / \mathrm{v}$ SDS, $40 \%$ v/v glycerol, $5 \% \mathrm{v} / \mathrm{v}$ $\beta$-mercaptoethanol, $0.04 \% \mathrm{v} / \mathrm{v}$ bromophenol blue, $30 \mathrm{~min}$, room temperature). From the DH379-labeled samples $10 \mu \mathrm{l}(14 \mu \mathrm{g}$ protein) of quenched reaction mixture was resolved on $10 \%$ acrylamide SDS-PAGE (180 V, $75 \mathrm{~min})$. The MB064and FP-BODIPY-labeled samples were combined $(1: 1 \mathrm{v} / \mathrm{v})$ and resolved together on $10 \%$ acrylamide SDS-PAGE ( $180 \mathrm{~V}, 75 \mathrm{~min})$. Fluorescence was measured using a Bio-Rad ChemiDoc MP system (fluorescence channel filters BODIPY, Cy2 (460-490 nm); BODIPY-TMR dye, Cy3 (520-545 nm); protein ladder, Cy5 $(625-650 \mathrm{~nm}))$. Gels were then stained using Coomassie staining and imaged for protein loading control. Fluorescence quantification was performed using ImageLab (Bio-Rad). Intensities were normalized to the DMSO control and corrected for protein loading by Coomassie staining.

Statistical analysis. Data were tested for significance with GraphPad v.6 using one-way ANOVA with Dunnett's correction for multiple comparisons. Two-way
ANOVA was used to evaluate LEI-401 versus vehicle in NAPE-PLD KO versus WT mice. $P<0.05$ was considered significant.

HPA axis activation. Pharmacological treatment and c-Fos labeling. All drugs were dissolved in 5\% DMSO, $5 \%$ Tween- 80 , and $90 \%$ saline the day of each experiment. The $\mathrm{CB}_{1}$ antagonist AM251 (3 $\mathrm{mg} \mathrm{kg}^{-1}$; Cayman Chemical), FAAH inhibitor URB597 ( $1 \mathrm{mg} \mathrm{kg}^{-1}$; Cayman Chemical) and the NAPE-PLD inhibitor LEI-410 $\left(30 \mathrm{mg} \mathrm{kg}^{-1}\right)$ were administered intraperitoneally (i.p., $10 \mathrm{ml} \mathrm{kg}{ }^{-1}$ ).

All animals (C57BL/6J mice) received $4 \mathrm{~d}$ of handling before test days. On test day, animals received drug injections 105 (AM251/vehicle) and $210 \mathrm{~min}$ (URB597/ LEI-410/vehicle) before perfusions. Animals were deeply anesthetized using pentobarbital injection and perfused intracardially with $4 \%$ paraformaldehyde and PBS. After perfusion, the brains were extracted and fixed in $4 \%$ paraformaldehyde at $4{ }^{\circ} \mathrm{C}$ overnight and then submerged in $30 \%$ sucrose in PBS at $4{ }^{\circ} \mathrm{C}$ for $48 \mathrm{~h}$. Using a mouse brain atlas, brains were mounted with optimal cutting temperature compound and sectioned $(40 \mu \mathrm{m})$ on a cryostat. Slices containing the PVN were placed in PBS until antibody treatment.

Sections were washed three times ( $10 \mathrm{~min}$ per wash) in a PBS and $0.1 \%$ Triton X-100 (PBST) solution before incubation in PBS blocking buffer containing 10\% normal donkey serum at room temperature for $1 \mathrm{~h}$. Sections were incubated in primary antibody rabbit anti-c-Fos (1:300 Cell Signaling) at $4{ }^{\circ} \mathrm{C}$ overnight. Tissue was then washed in PBST solution three more times (10 min each) and then incubated in donkey antirabbit Cy3 (1:100 JacksonImmuno) at room temperature for $2 \mathrm{~h}$. Sections were washed in PBST three more times, then mounted in PBS and examined using a Leica fluorescent microscope. Two slices containing the PVN were collected from each specimen. Grayscale images were taken of both hemispheres separately for each slice. All images within experiments were obtained under the same exposure and magnification $(20 \times)$. Images were processed on ImageJ, where they were subjected to a brightness threshold before c-Fos labeled cells were counted based on size criteria set for each experiment. Number of labeled cells inside a defined region $\left(24,614.47 \mu \mathrm{m}^{2}\right)$ that met the set criteria were measured and the density of c-Fos expressing cells was compared across drug groups.

CORT measurements. To measure circulating CORT levels, tail blood was taken 45 (AM251/vehicle) and $150 \mathrm{~min}$ (URB597/LEI-410/vehicle) after injections. Blood samples were centrifuged at 3,000 r.p.m. for $20 \mathrm{~min}$ at $4^{\circ} \mathrm{C}$. Serum was stored at $-80^{\circ} \mathrm{C}$ until analysis with an enzyme-linked immunosorbent assay kit (Arbor Assays) by following the manufacturer's instructions. Samples were tested in triplicate and diluted 1:1,000 to make sure levels fitted into the standard curve. Values were normalized to the control (vehicle) group of each experiment.

Behavioral testing. Subjects. Subjects were male 7-12-week-old C57BL/6J mice obtained from The Jackson Laboratory. Mice were housed two per cage in a temperature- and humidity-controlled vivarium under a $12 \mathrm{~h}$ light/dark cycle (lights on 6:00h). Experimental procedures were performed in accordance with the National Institutes of Health Guide for Care and Use of Laboratory Animals and approved by the local Animal Care and Use Committee. The number of mice used in each experiment is indicated in the figure legends. Before testing, each mouse was handled for $2 \mathrm{~min}$ per day for $5 \mathrm{~d}$. Mice were acclimated in a room next to test area $1 \mathrm{~h}$ before the experiment.

Fear conditioning. Fear conditioning was conducted in 'context A': a $30 \times 25 \times$ $21 \mathrm{~cm}^{3}$ operant chamber (Med Associates, Inc.) with metal walls and a metal rod floor. To provide an additional olfactory cue, the chamber was cleaned between subjects with a $79.5 \%$ water: $19.5 \%$ ethanol: $1 \%$ vanilla extract solution. After a 180-s stimulus-free context acclimation, there were three lots of pairings of a $30-\mathrm{s}, 75-\mathrm{dB}$ white noise cue (conditioned stimulus) and a 2-s 0.6-mA scrambled coterminating footshock (unconditioned stimulus). Between each stimulus was an increasing interpairing interval (60-90-120 s). Following the last pairing was a 120 -s stimulus-free period. Stimulus presentation waps controlled by the Med Associates VideoFreeze system (Med Associates). Freezing (no visible movement except respiration) was scored every $5 \mathrm{~s}$ by an observer blind to condition/treatment and converted to a percentage ((freezing observations/total observations) $\times 100)$.

Fear extinction training. Fear extinction training occurred the following day in 'context B': a $27 \times 27 \times 14 \mathrm{~cm}^{3}$ operant chamber with transparent walls and a floor covered with wood chips, cleaned between subjects with a $99 \%$ water: $1 \%$ acetic acid solution and housed in a different room from training. One hour and fourty-five minutes before extinction, mice were injected with one of four combinations of drug intervention (see the section Pharmacological treatments). After a 180 -s stimulus-free baseline, there were $50 \times 30$-s conditioned stimulus presentations (5-s interconditioned stimulus interval).

Extinction retrieval. Extinction retrieval was tested $1 \mathrm{~d}$ and $10 \mathrm{~d}$ after extinction training in context $\mathrm{B}$, via $5 \times 30$-s conditioned stimulus presentations $(5-\mathrm{s}$ interconditioned stimulus interval) beginning after a 180-s stimulus-free baseline. The mean number of freezing observations per baseline period and $5 \times$ conditioned 
stimulus block was converted to a percentage ((number of freezing observations/ total number of observations per period $) \times 100$ ) for analysis.

Statistical analysis. The effects of treatment and trial-block on freezing during extinction training were analyzed using two-way ANOVA, with repeated measures for a trial block. The effect of drug treatment on freezing during retrieval was analyzed using ANOVA.

Pharmacological treatments. Pre-extinction treatment of NAPE-PLD inhibitor LEI-401 (30 $\mathrm{mg} \mathrm{kg}^{-1}$, i.p.), FAAH inhibitor AM3506 (1 $\mathrm{mg} \mathrm{kg}^{-1}$, i.p. $)$ and their vehicle controls were administered $1 \mathrm{~h} 45 \mathrm{~min}$ before the extinction training in two consecutive injections. Every injection combination led to four groups: vehicle + vehicle, vehicle + AM3506, vehicle + LEI-401 and AM3506 + LEI401. LEI-401 stock ( $30 \mathrm{mg} \mathrm{ml}^{-1}$ ) was prepared in DMSO. Aliquots of LEI-401 were mixed with Tween-80 and sterile distilled $\mathrm{H}_{2} \mathrm{O}(1: 1: 8)$ and AM3506 stock $\left(10 \mathrm{mg} \mathrm{ml}^{-1}\right)$ was prepared in DMSO and mixed with saline (1:9) just before administration (in a volume of $10 \mathrm{ml} \mathrm{kg}^{-1}$ ) before extinction training.

Reporting Summary. Further information on research design is available in the Nature Research Reporting Summary linked to this article.

\section{Data availability}

All data generated or analyzed during this study are included in this published article (and its Supplementary Information files) or are available from the corresponding author on reasonable request. The mass spectrometry proteomics data (raw data and ISOQuant output tables for proteins groups and peptides) have been deposited in the ProteomeXchange Consortium (http://proteomecentral.proteomexchange.org) via the PRIDE partner repository with the dataset identifier PXD017586.

\section{References}

51. van der Wel, T. et al. A natural substrate-based fluorescence assay for inhibitor screening on diacylglycerol lipase $\alpha$. J. Lipid Res. 56, 927-935 (2015).

52. Baggelaar, M. P. et al. Development of an activity-based probe and in silico design reveal highly selective inhibitors for diacylglycerol lipase- $\alpha$ in brain. Angew. Chem. Int. Ed. 52, 12081-12085 (2013).

53. Navia-Paldanius, D., Savinainen, J. R. \& Laitinen, J. T. Biochemical and pharmacological characterization of human $\alpha / \beta$-hydrolase domain containing 6 (ABHD6) and 12 (ABHD12). J. Lipid Res. 53, 2413-2424 (2012).

54. Soethoudt, M. et al. Cannabinoid $\mathrm{CB}_{2}$ receptor ligand profiling reveals biased signalling and off-target activity. Nat. Commun. 8, 13958 (2017).

55. van Esbroeck, A. C. M. et al. Activity-based protein profiling reveals off-target proteins of the FAAH inhibitor BIA 10-2474. Science 356, 1084-1087 (2017).

56. Council, N. R. Guide for the Care and Use of Laboratory Animals 8th edn (The National Academies Press, 2011).

57. Kilkenny, C., Browne, W., Cuthill, I. C., Emerson, M. \& Altman, D. G. Animal research: reporting in vivo experiments: the ARRIVE guidelines. Br. J. Pharmacol. 160, 1577-1579 (2010).
58. Cinar, R. et al. Hybrid inhibitor of peripheral cannabinoid-1 receptors and inducible nitric oxide synthase mitigates liver fibrosis. JCI Insight 1, e87336 (2016).

59. Mukhopadhyay, B. et al. Hyperactivation of anandamide synthesis and regulation of cell-cycle progression via cannabinoid type $1\left(\mathrm{CB}_{1}\right)$ receptors in the regenerating liver. Proc. Natl Acad. Sci. USA 108, 6323-6328 (2011).

\section{Acknowledgements}

The research leading to these results has received support from the Innovative Medicines Initiative Joint Undertaking under grant agreement no. 115489, resources of which are composed of financial contribution from the European Union's Seventh Framework Programme (no. FP7/2007-2013) and EFPIA companies' in kind contribution. M.v.d.S. was supported by a VICI-grant from the Netherlands Organization for Scientific Research and funding from Oncode Institute. Leiden University, Faculty of Science 'Profiling Programme: Endocannabinoids' is also acknowledged for financial support to E.D.M., V.K., T.H. and M.v.d.S. This research was also supported by National Institutes of Health National Institute on Drug Abuse (grant nos. R01DA039942 and P30DA0339340), Canadian Institutes of Health Research (grant no. FDN-143329 to M.N.H.) as well as start-up funds from the VCU School of Pharmacy to A.H.L. and the Intramural Research Program of NIAAA/NIH (to P.P., O.G.-C., L.I.C., C.M.D. and A.H.). We kindly acknowledge the Pharmaceutical Sciences division of F. Hoffman-La Roche Ltd for their technical assistance with the drug metabolism and pharmacokinetics experiments.

\section{Author contributions}

E.D.M., T.H., M.N.H, P.P., A.H.L. and M.v.d.S. conceived the project and designed the experiments. J.W., H.v.d.H. and C.A.A.v.B. performed the HTS study. E.D.M. and I.K. synthesized the compounds. E.D.M., A.C.M.v.E., A.M.F.v.d.G., A.M., T.v.d.W, M.S., M.J., T.J.W. and A.P.A.J., performed biochemical and cellular experiments. A.T.B. and B.I.F. performed the proteomics measurements. V.K. and X.D. performed the in vitro and cellular lipidomics measurements. E.D.M., M.M., R.C., G.N.P., D.O., Z.V.V., J.P., C.M., G.D., J.K.P., A.P.A.J., B.I.F., M.W., U.G. and M.N.H. performed in vivo pharmacokinetics, lipidomics and behavioral studies. O.G.-C., L.I.C., C.M.D. and A.H. designed, performed and analyzed fear extinction behavior. E.D.M., M.W., U.G., B.F.C., M.W.B., H.v.d.H., C.A.A.v.B., P.P., A.H.L. and M.v.d.S analyzed the data and wrote the manuscript.

\section{Competing interests}

E.M., I.K. C.B. and M.v.d.S. are listed as inventors on patent application WO 2019/229250 A1 filed by Leiden University in which inhibitors of NAPE-PLD are disclosed.

\section{Additional information}

Supplementary information is available for this paper at https://doi.org/10.1038/ s41589-020-0528-7.

Correspondence and requests for materials should be addressed to M.v.S.

Reprints and permissions information is available at www.nature.com/reprints. 


\section{Reporting Summary}

Nature Research wishes to improve the reproducibility of the work that we publish. This form provides structure for consistency and transparency in reporting. For further information on Nature Research policies, see Authors \& Referees and the Editorial Policy Checklist.

\section{Statistics}

For all statistical analyses, confirm that the following items are present in the figure legend, table legend, main text, or Methods section.

$\mathrm{n} / \mathrm{a}$ Confirmed

$\bigotimes$ The exact sample size $(n)$ for each experimental group/condition, given as a discrete number and unit of measurement

$\square$ \ A statement on whether measurements were taken from distinct samples or whether the same sample was measured repeatedly

$\square$ The statistical test(s) used AND whether they are one- or two-sided

Only common tests should be described solely by name; describe more complex techniques in the Methods section.

Х A description of all covariates tested

$\square$ \ A description of any assumptions or corrections, such as tests of normality and adjustment for multiple comparisons

A full description of the statistical parameters including central tendency (e.g. means) or other basic estimates (e.g. regression coefficient)

AND variation (e.g. standard deviation) or associated estimates of uncertainty (e.g. confidence intervals)

For null hypothesis testing, the test statistic (e.g. $F, t, r$ ) with confidence intervals, effect sizes, degrees of freedom and $P$ value noted

Give $P$ values as exact values whenever suitable.

Х $\square$ For Bayesian analysis, information on the choice of priors and Markov chain Monte Carlo settings

Х $\square$ For hierarchical and complex designs, identification of the appropriate level for tests and full reporting of outcomes

$\bigotimes \square$ Estimates of effect sizes (e.g. Cohen's $d$, Pearson's $r$ ), indicating how they were calculated

Our web collection on statistics for biologists contains articles on many of the points above.

\section{Software and code}

Policy information about availability of computer code

Data collection not applicable

Data analysis SDS-PAGE analysis was performed with Image Lab v6 (Bio-Rad). Statistical analysis was performed with Graphpad Prism v6. Proteomic analysis was performed with ProteinLynx Global SERVER ${ }^{\text {TM }}$ (PLGS, Waters) and ISOQuant v1.5 (http://www.immunologie.uni-mainz.de/ isoquant/). qPCR experiments were analyzed with CFX Manager software (Bio-rad). For lipidomics experiments in cells and lysates data was analyzed with MassLynx 4.1 (Waters). Mouse plasma pharmacokinetic analysis of LEl-401 was performed using Phoenix WinNonlin 6.4 software (Certara). Brain pharmacokinetic experiments with LEI-401 were analyzed with MassHunter Workstation Optimizer software (Agilent Technologies).

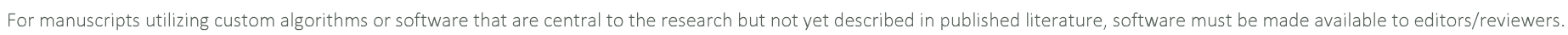
We strongly encourage code deposition in a community repository (e.g. GitHub). See the Nature Research guidelines for submitting code \& software for further information.

\section{Data}

Policy information about availability of data

All manuscripts must include a data availability statement. This statement should provide the following information, where applicable:

- Accession codes, unique identifiers, or web links for publicly available datasets

- A list of figures that have associated raw data

- A description of any restrictions on data availability

All data is provided in the manuscript or Supplementary information. Supplementary Table 7 describes proteomic data including UniprotID accession codes for detected proteins. 
Please select the one below that is the best fit for your research. If you are not sure, read the appropriate sections before making your selection.

\ Life sciences

Behavioural \& social sciences

Ecological, evolutionary \& environmental sciences

For a reference copy of the document with all sections, see nature.com/documents/nr-reporting-summary-flat.pdf

\section{Life sciences study design}

All studies must disclose on these points even when the disclosure is negative.

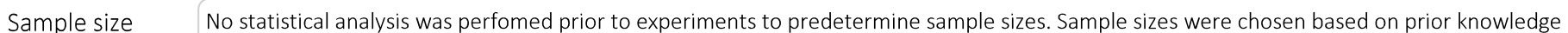
in the respective experiments and their intrinsic variability as performed in previous studies (Ogasawara et al, PNAS, 2016 and Soethoudt et al., Nat. Commun., 2017)

Data exclusions No data were excluded.

Replication All the in vitro and cellular experiments were performed at least in two independent experiments ( $\mathrm{N}=2$ ) with biological replicates ( $\mathrm{n}=2)$, showing reproducible results. The in vivo lipidomics was performed in a time-dependent and in a dose-dependent manner, producing similar effects with $n=5-11$ animals. The behavioral studies were performed in two independent experiments, giving similar effects with $n=9-13$ animals.

Randomization Animals were allocated in a randomized fashion into experimental groups. The behavioral studies were conducted in accordance with the ARRIVE guidelines for reporting experiments involving animals.

Blinding Investigators were blinded to condition and treatment when scoring freezing behavior. All other experiments are measurements of enzyme activity, protein labeling, metabolites and are not based on subjective assessment of animal behavior.

\section{Reporting for specific materials, systems and methods}

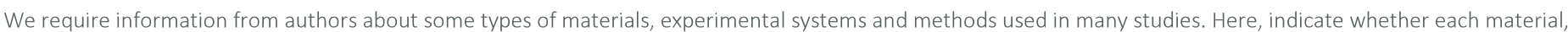

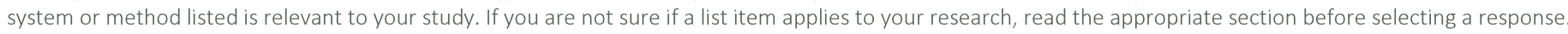

\begin{tabular}{|c|c|c|c|}
\hline \multicolumn{2}{|c|}{ Materials \& experimental systems } & \multicolumn{2}{|c|}{ Methods } \\
\hline $\mathrm{n} / \mathrm{a}$ & Involved in the study & $\mathrm{n} / \mathrm{a}$ & Involved in the study \\
\hline & Х Antibodies & Х & ChIP-seq \\
\hline & $\bigotimes$ Eukaryotic cell lines & Х & Flow cytometry \\
\hline Х & $\square$ Palaeontology & Х & MRI-based neuroimaging \\
\hline & Х Animals and other organisms & & \\
\hline Х & Human research participants & & \\
\hline Х & $\square$ Clinical data & & \\
\hline
\end{tabular}

\section{Antibodies}

Antibodies used

Primary antibodies:

Anti-NAPE-PLD (Abcam, ab95397, 1:200)

Anti-FLAG (Sigma Aldrich, F3165, 1:5000)

Anti-alfa-tubulin (Genetex, GTX76511, 1:5000)

Anti-beta-actin (Abcam, ab8226, 1:5000)

Anti-cFos (Cell Signaling, \#2250, 1:300)

Secondary antibodies:

Goat-anti-rabbit-HRP (Santa Cruz, sc-2030, 1:2000)

Goat-anti-mouse-HRP (Santa Cruz, sc-2005, 1:5000)

Goat-anti-rat (Santa Cruz, sc-2032, 1:5000)

Donkey-anti-rabbit (JacksonImmuno, 711-165-152, 1:100)

Validation

All antibodies were sourced commercially. Anti-NAPE-PLD was confirmed using human and mouse NAPE-PLD overexpressing HEK293T lysate. Other validation has been performed in previous studies (van Esbroeck et al. Front. Neurosci., 2019 and Baggelaar et al. JACS, 2015). 
Policy information about cell lines

Cell line source(s)

HEK293T and Neuro-2a were from ATCC.

Authentication

The cell lines used have been authenticated by the ATCC.

Mycoplasma contamination

Cell lines were regularly tested for mycoplasma contamination and were tested negative.

Commonly misidentified lines

(See ICLAC register)

No misidentified cell lines were used.

\section{Animals and other organisms}

Policy information about studies involving animals; ARRIVE guidelines recommended for reporting animal research

Laboratory animals

Wild animals

Field-collected samples

Ethics oversight
For the in vivo PK, lipidomics and behavioral experiments C57BL/6J mice (Jackson Laboratory, Bar Harbor, Maine, USA) were used. WT and NAPE-PLD KO mice from a mixed 129SvJ-C57BL/6J background were also used (Virginia Polytechnic Institute and State University, Blacksburg, Virginia, USA). 7-12-week-old male and female mice were used in this study.

No wild animals were used in this study.

No field-collected samples were used in this study.

Animal protocols were approved by the Institutional Animal Care and Use Committee at Virginia Commonwealth University, the National Institute on Alcohol Abuse and Alcoholism (NIAAA), National Institute of Health (NIH) and Bundesamt für Lebensmittelsicherheit und Veterinärwesen (BLV) der Schweizerischen Eidgenossenschaft.

Note that full information on the approval of the study protocol must also be provided in the manuscript. 